\title{
Operando identification of site-dependent water oxidation activity on ruthenium dioxide single-crystal surfaces
}

Rao, Reshma R.; Kolb, Manuel J.; Giordano, Livia; Pedersen, Anders Filsøe; Katayama, Yu; Hwang, Jonathan; Mehta, Apurva; You, Hoydoo; Lunger, Jaclyn R.; Zhou, Hua

Total number of authors:

15

Published in:

Nature Catalysis

Link to article, DOI:

10.1038/s41929-020-0457-6

Publication date:

2020

Document Version

Peer reviewed version

Link back to DTU Orbit

Citation (APA):

Rao, R. R., Kolb, M. J., Giordano, L., Pedersen, A. F., Katayama, Y., Hwang, J., Mehta, A., You, H., Lunger, J. R., Zhou, H., Halck, N. B., Vegge, T., Chorkendorff, I., Stephens, I., \& Shao-Horn, Y. (2020). Operando identification of site-dependent water oxidation activity on ruthenium dioxide single-crystal surfaces. Nature Catalysis, 3(6), 516-525. https://doi.org/10.1038/s41929-020-0457-6

\section{General rights}

Copyright and moral rights for the publications made accessible in the public portal are retained by the authors and/or other copyright owners and it is a condition of accessing publications that users recognise and abide by the legal requirements associated with these rights.

- Users may download and print one copy of any publication from the public portal for the purpose of private study or research.

- You may not further distribute the material or use it for any profit-making activity or commercial gain

- You may freely distribute the URL identifying the publication in the public portal 


\title{
Operando identification of site-dependent water oxidation activity on ruthenium dioxide single-crystal surfaces
}

\author{
Reshma R. Rao ${ }^{1,9,12} \bowtie$, Manuel J. Kolb ${ }^{2,12}$, Livia Giordano, ${ }^{1,2}$, Anders Filsøe Pedersen ${ }^{3}$, \\ Yu Katayama ${ }^{2,10}$, Jonathan Hwang ${ }^{4}$, Apurva Mehta ${ }^{5}$, Hoydoo You ${ }^{6}$, Jaclyn R. Lunger ${ }^{4}$, Hua Zhou $\left({ }^{7}\right.$, \\ Niels Bendtsen Halck ${ }^{8}$, Tejs Vegge $\mathbb{D}^{8}$, Ib Chorkendorff $\mathbb{B}^{3}$, Ifan E. L. Stephens $\mathbb{1}^{3,11}$ \\ and Yang Shao-Horn 1 1,2,4凶
}

\begin{abstract}
Understanding the nature of active sites is central to controlling (electro)catalytic activity. Here we employed surface X-ray scattering coupled with density functional theory and surface-enhanced infrared absorption spectroscopy to examine the oxygen evolution reaction on $\mathrm{RuO}_{2}$ surfaces as a function of voltage. At $1.5 \mathrm{~V}_{\mathrm{RHE}}$ our results suggest that there is an -00 group on the coordinatively unsaturated ruthenium ( $\left(\mathrm{u}_{\mathrm{cus}}\right)$ site of the (100) surface (and similarly for (110)), but adsorbed oxygen on the $\mathrm{Ru}_{\mathrm{cus}}$ site of (101). Density functional theory results indicate that the removal of -00 from the $\mathrm{Ru}_{\mathrm{cus}}$ site, which is stabilized by a hydrogen bond to a neighbouring -OH (-OO-H), could be the rate-determining step for (100) (similarly for (110)), where its reduced binding on (100) increased activity. A further reduction in binding energy on the $\mathrm{Ru}_{\mathrm{cus}}$ site of (101) resulted in a different rate-determining step $\left(-\mathrm{O}+\mathrm{H}_{2} \mathrm{O}-\left(\mathrm{H}^{+}+\mathrm{e}^{-}\right) \rightarrow-0 \mathrm{O}-\mathrm{H}\right)$ and decreased activity. Our study provides molecular details on the active sites, and the influence of their local coordination environment on activity.
\end{abstract}

C atalysing the oxygen evolution reaction (OER) is pivotal for enabling efficient production of energy carriers such as hydrogen $^{1}$ and ammonia ${ }^{2}$, synthetic carbon-neutral fuels by $\mathrm{CO}_{2}$ reduction ${ }^{3}$, and metals from metal oxides. ${ }^{4}$. Rutile $\mathrm{RuO}_{2}$ has been considered a benchmark OER catalyst in acidic solutions, where most other oxides are unstable ${ }^{5-7}$. Although bulk rutile $\mathrm{RuO}_{2}$ consists of a ruthenium atom octahedrally coordinated to six oxygen atoms, having each oxygen atom as threefold coordinated ${ }^{6,7}$, surfaces can lead to undercoordinated metal and oxygen sites being different from those of the bulk and these can catalyse bond making and breaking as they can interact with reacting molecules to compensate for undercoordination ${ }^{8,9}$. Theoretical ${ }^{10,11}$ and experimental ${ }^{12-18}$ studies on the (electro)catalytic activity of $\mathrm{RuO}_{2}$ have been focused on the (110) surface, where terraces expose a fully coordinated bridge ruthenium $\left(\mathrm{Ru}_{\mathrm{BRI}}\right)$ site and a coordinatively unsaturated site $\left(\mathrm{Ru}_{\mathrm{CuS}}\right)$ with fivefold coordination $\left(\mathrm{Ru}_{\mathrm{CUS}}\right)$, which are bonded to threefold-coordinated oxygens $\left(\mathrm{O}_{3 c}\right)^{6}$. The $\mathrm{Ru}_{\text {Cus }}$ site has been identified as the active site for gas-phase oxidation of small molecules such as $\mathrm{CO}\left(\right.$ refs. $\left.{ }^{12,13}\right), \mathrm{CH}_{3} \mathrm{OH}\left(\right.$ ref. $\left.{ }^{14}\right), \mathrm{HCl}\left(\right.$ ref. $\left.{ }^{15}\right), \mathrm{NH}_{3}$ (ref. ${ }^{16}$ ) and $\mathrm{NO}\left(\right.$ ref. ${ }^{17}$ ). More recently, the $\mathrm{Ru}_{\mathrm{Cus}}$ on $(110)$ has been shown to catalyse the OER in acid ${ }^{18}$ by electron-coupled deprotonation of water. Specifically, adsorbed water is deprotonated on the $\mathrm{Ru}_{\mathrm{Cus}}$ to form $-\mathrm{OH}$ and $-\mathrm{O}$; the adsorption and dehydrogenation of a second water molecule creates an -OO species on the $\mathrm{Ru}_{\mathrm{CUS}}$ that forms a strong hydrogen bond to a neighbouring $-\mathrm{OH}$ group $(-\mathrm{OO}-\mathrm{H})$; and the final deprotonation of $-\mathrm{OO}-\mathrm{H}$ (considered to be the rate-determining step (RDS)) leads to the evolution of oxygen ${ }^{18}$. Unfortunately, $\mathrm{Ru}_{\text {CUS }}$ on $\mathrm{RuO}_{2}(110)$ binds the $-\mathrm{OO}$ intermediate more strongly than is optimal ${ }^{18}$.

Using surface facets beyond $\mathrm{RuO}_{2}(110)$ can allow for an increase in the active site $\left(\mathrm{Ru}_{\text {Cus }}\right)$ density and tuning of the electronic structure of the $\mathrm{Ru}_{\text {CUS }}$ to enhance OER activity. Although the (100) $\left(7 \mathrm{Ru}_{\text {CUs }} \mathrm{nm}^{-2}\right)$ and $(101)\left(8 \mathrm{Ru}_{\text {CUS }} \mathrm{nm}^{-2}\right)$ facets have more $\mathrm{Ru}_{\text {CUs }}$ sites than (110) $\left(5 \mathrm{Ru}_{\text {CUS }} \mathrm{nm}^{-2}\right)$, the OER activity enhancement of (100) and (101) relative to (110) is not proportional to the $\mathrm{Ru}_{\text {Cus }}$ densities, with OER activities of around 7 and 2.5 times greater than $(110)^{19}$, respectively, at $1.50 \mathrm{~V}_{\mathrm{RHE}}$. This observation suggests that $\mathrm{Ru}_{\mathrm{CUS}}$ sites might have distinctive electronic structures and deprotonation energetics of adsorbed intermediates on different $\mathrm{RuO}_{2}$ surfaces. This hypothesis is supported by recent work showing that $\mathrm{Ru}_{\text {Cus }}$ sites on (110), (100) and (101) bind and interact with water differently. On the (110) surface, every second water molecule dissociates to form an $-\mathrm{OH}$ on $\mathrm{Ru}_{\mathrm{CuS}}$, with the proton transferred to the neighbouring oxygen on $\mathrm{Ru}_{\mathrm{BRI}}$ (refs. ${ }^{18,20,21}$ ); on the other hand, every water molecularly adsorbs onto the $\mathrm{Ru}_{\mathrm{CuS}}$ of $(100)^{22}$, whereas every water dissociatively adsorbs onto the $\mathrm{Ru}_{\mathrm{CUS}}$ of (101), with transfer of the proton to the neighbouring bridging oxygen ${ }^{22}$. Further support comes from the fact that surface redox peaks measured on oriented

'Department of Mechanical Engineering, Massachusetts Institute of Technology, Cambridge, Massachusetts, USA. ${ }^{2}$ Research Laboratory of Electronics, Massachusetts Institute of Technology, Cambridge, Massachusetts, USA. ${ }^{3}$ Section for Surface Physics and Catalysis, Department of Physics, Technical University of Denmark, Kongens Lyngby, Denmark. ${ }^{4}$ Department of Materials Science and Engineering, Massachusetts Institute of Technology, Cambridge, Massachusetts, USA. ${ }^{5}$ SLAC National Accelerator Laboratory, Menlo Park, California, USA. ${ }^{6}$ Materials Science Division, Argonne National Laboratory, Lemont, Illinois, USA. ${ }^{7}$ X-ray Science Division, Argonne National Laboratory, Lemont, Illinois, USA. ${ }^{8}$ Department of Energy Conversion and Storage, Technical University of Denmark, Kongens Lyngby, Denmark. 'Present address: Research Laboratory of Electronics, Massachusetts Institute of Technology, Cambridge, Massachusetts, USA. ${ }^{10}$ Present address: Department of Applied Chemistry, Graduate School of Sciences and Technology for Innovation, Yamaguchi University, Tokiwadai, Japan. "Present address: Royal School of Mines, Imperial College London, South Kensington Campus, London, UK. 12These authors contributed equally: Reshma R Rao, Manuel J Kolb. $\varpi_{e}$-mail: reshmar@mit.edu; shaohorn@mit.edu 
films in acid or base are facet-dependent ${ }^{23,24}$, which has been correlated with adsorption energetics (for example, the metal-oxygen binding energy, $\left.\Delta G_{\mathrm{O}}-\Delta G_{\mathrm{OH}}\right)^{18,25,26}$. Specifically, the redox peak just before the OER is shifted to more positive potentials for (101) compared with (110) and $(100)^{27,28}$, suggesting a weakening of the binding energy of the surface intermediates on (101).

In this study we aim to compare the electronic structure of $\mathrm{Ru}_{\mathrm{CUS}}$ sites across these three surfaces, as well as the molecular details and energetics of adsorbates at potentials relevant to the OER in acid, to seek the physical origin of their activity differences. Density functional theory (DFT) results show that increasing the degree of undercoordination of the surface oxygen bonded to $\mathrm{Ru}_{\mathrm{CUS}}$ and/or increasing the surface $\mathrm{Ru}-\mathrm{O}-\mathrm{Ru}$ bond angle on (100) and (101) can decrease the binding energy of OER-relevant intermediates. A decrease in the binding energy of the -OO group on the $\mathrm{Ru}_{\mathrm{CUS}}$ of (100) relative to (110) is correlated with increased measured and computed intrinsic OER activity (where the deprotonation of $-\mathrm{OO}-\mathrm{H}$ is rate determining); however, a further decrease in -OO binding on $\mathrm{Ru}_{\mathrm{CuS}}$ of (101) results in the second water dissociation step $\left(-\mathrm{O}+\mathrm{H}_{2} \mathrm{O}-\left(\mathrm{H}^{+}+\mathrm{e}^{-}\right) \rightarrow-\mathrm{OO}-\mathrm{H}\right)$ becoming rate determining, having measured and computed intrinsic OER activity that is lower than on the (100) surface. Such adsorbate intermediates on $\mathrm{Ru}_{\mathrm{CUS}}$ of (100) and (101) are verified by synchrotron-based in situ surface X-ray scattering as a function of potential in acid, where the assignment of the nature of the proposed structures at potentials relevant to OER is aided by DFT calculations (similar to previous work $\left.{ }^{18}\right)$. Further evidence that the reaction mechanism at $\mathrm{Ru}_{\mathrm{CUS}}$ catalyses the OER comes from in situ Fourier transform-infrared (FT-IR) spectroscopy detection of -OO-like species at OER-relevant potentials. Finally, such molecular details on the $\mathrm{Ru}_{\mathrm{CUS}}$ site gained from single-crystal surfaces are used to explain the redox properties and OER activity of polycrystalline surfaces and nanoparticles.

\section{Results}

Surface-dependent electronic structure. First we consider the effect of the coordination of surface oxygen atoms on the surface electronic structure and adsorbate energetics of $\mathrm{Ru}_{\mathrm{CUS}}$. Although the (110) surface has both $\mathrm{Ru}_{\mathrm{CUS}}$ and $\mathrm{Ru}_{\mathrm{BRI}}$ sites, the (100) and (101) surfaces have only $\mathrm{Ru}_{\text {CUS }}$. The $\mathrm{Ru}_{\text {CUS }}$ has a $\mathrm{RuO}_{5}$ coordination with four neighbouring equatorial oxygen atoms and one apical binding site; however, the coordination of the equatorial oxygen atoms is different for the three surfaces. All four neighbouring equatorial oxygens on (110) are $\mathrm{O}_{3 c}$, whereas two of the four equatorial oxygen atoms that are bound to the $\mathrm{Ru}_{\mathrm{CUS}}$ site on (100) and (101) are twofold-coordinated $\left(\mathrm{O}_{2 c}\right)$, and the other two are $\mathrm{O}_{3 c}$ (Fig. 1a,b). The $\mathrm{Ru}_{\mathrm{CuS}}$ sites in (100) and (101), with undercoordinated equatorial oxygens, have an $\mathrm{O}_{2 c} 2 p$ band centre further away from the Fermi level (Fig. 1c,d and Supplementary Fig. 1) and stronger binding to equatorial oxygen $\left(\mathrm{Ru}_{\mathrm{CuS}}-\mathrm{O}_{2 \mathrm{c}}\right)$ compared with (110), which is in agreement with previous work on perovskites ${ }^{29,30}$. This result is also in agreement with previous work of pseudo-valence charge-density analysis, showing that $\mathrm{Ru}_{\mathrm{CUS}}$ on the (100) surface has different hybridization with surface oxygen than that of bulk ruthenium, whereas $\mathrm{Ru}_{\mathrm{CUS}}$ on (110) surface does not exhibit this difference $^{31}$. Consequently, Bader charge analysis of the $\mathrm{Ru}_{\mathrm{CUS}}$ site shows that it is less oxidized for the (110) surface than the (100) and (101) surfaces, where the $d$ band centre for the $\mathrm{Ru}_{\mathrm{CuS}}$ sites scales with the Bader charge (Supplementary Tables 1 and 2 and Supplementary Fig. 3). Furthermore, (100) and (101) differ in the orientation of the polyhedra on the surface: two adjacent polyhedra with undercoordinated $\mathrm{O}_{2 c}$ and $\mathrm{Ru}_{\mathrm{CUS}}$ sites share an edge on the (100) surface (with a $\mathrm{Ru}_{\mathrm{CUS}}-\mathrm{O}_{2 \mathrm{c}}-\mathrm{Ru}_{\mathrm{CUS}}$ bond angle of $101^{\circ}$ ), whereas they share only a corner on the (101) surface (with a $\mathrm{Ru}_{\mathrm{CUS}}-\mathrm{O}_{2 \mathrm{c}}-\mathrm{Ru}_{\mathrm{CUS}}$ bond angle of $129^{\circ}$ ) for an ideal surface (Fig. 1b). Increasing this bond angle further lowers the oxygen $2 p$ band centre from the Fermi level and increases the $\mathrm{Ru}_{\mathrm{Cus}}-\mathrm{O}_{2 c}$ bond strength (Fig. 1c, d and Supplementary Fig. 1). Stronger bonds between $\mathrm{Ru}_{\mathrm{CUS}}$ and $\mathrm{O}_{2 \mathrm{c}}$ in the order $(101)>(100)>(110)$ are accompanied by the Fermi level moving closer to the surface $\mathrm{O}_{1 \mathrm{c}} 2 p$ band centre and a decrease in the binding energetics of $\mathrm{Ru}_{\mathrm{CUS}}$ sites with apical adsorbates (for example, $\mathrm{Ru}_{\mathrm{CuS}}-\mathrm{O}_{1 \mathrm{c}}$ ) in the trend of $(110)>(100)>(101)$ (see Fig. 1d and Supplementary Fig. 2). This surface $\mathrm{O}_{1 \mathrm{c}} 2 p$ band centre has recently been proposed as a site-specific descriptor of OER activity for a library of oxygen sites on a kinked $\mathrm{RuO}_{2}(121)$ surface from DFT studies ${ }^{32}$. Lowering the coordination of oxygen atoms bound to $\mathrm{Ru}_{\mathrm{CUS}}$ from (110) to (100) decreases the binding energy of apical adsorbed oxygen $\left(\mathrm{O}_{1 \mathrm{c}}\right)$ by $0.04 \mathrm{eV}$. The influence of the surface $\mathrm{Ru}_{\mathrm{CUS}}-\mathrm{O}_{2 \mathrm{c}}-\mathrm{Ru}_{\mathrm{CUS}}$ bond angle is more substantial, where increasing the angle from $101^{\circ}$ on (100) to $129^{\circ}$ on (101) decreases the oxygen $\left(\mathrm{O}_{1 \mathrm{c}}\right)$ binding energy by $0.14 \mathrm{eV}$. The local coordination of equatorial oxygen for $\mathrm{Ru}_{\mathrm{CUS}}$ thus results in a change in the electronic structure and binding energetics of apical adsorbates on $\mathrm{Ru}_{\mathrm{CUS}}$, with the binding energy decreasing in the order $(110)>(100)>(101)$.

Surface-dependent reaction energetics of OER. We computed the free energies of OER intermediates on different $\mathrm{Ru}_{\text {Cus }}$ sites of $\mathrm{RuO}_{2}(100)$ and (101) surfaces and compared them with the (110) surface $^{18}$. A four proton-electron concerted process for the OERinvolving six intermediates, as reported previously for the (110) surface ${ }^{18}$-is shown in Fig. 2 and Supplementary Table 3. The process starts with an empty $\mathrm{Ru}_{\text {CUS }}$ (step 1) on an otherwise oxygenated surface. Water adsorbs apically on $\mathrm{Ru}_{\mathrm{CUS}}(2)$ and is deprotonated successively to form $-\mathrm{OH}(3)$ and $-\mathrm{O}(4)$ species. Subsequently, a second water molecule adsorbs and is deprotonated to form an $-\mathrm{OOH}$ group (5), which is unstable and donates its proton to a neighbouring oxygen site to form an -OO species (6) (Supplementary Fig. 4). The proton of the $-\mathrm{OOH}$ group is transferred barrierlessly when the initial configuration of the DFT calculation is the one in which the $-\mathrm{OOH}$ group points to a neighbouring oxygen site. The species thus formed is similar in nature to a negatively charged species, $-\mathrm{OO}^{-}$, which is based on the $\mathrm{O}-\mathrm{O}$ bond length of $\sim 1.28 \AA$ and can thus interact strongly with a neighbouring proton (Supplementary Table 4). The removal of the proton-stabilizing -OO species results in the release of molecular oxygen (7). Steps from the formation of $-\mathrm{O}(4)$ to the release of molecular oxygen (7) on $\mathrm{Ru}_{\mathrm{CUS}}$ could be uphill at $1.5 \mathrm{~V}_{\text {DFT-RHE}}$. The oxygen (4) and proton-stabilized -OO intermediate $(-\mathrm{OO}-\mathrm{H})(6)$ binding on $\mathrm{Ru}_{\mathrm{CUS}}$ decreases from $(110)>(100)>(101)$. The binding energy for $-\mathrm{O}(4)$ on the $\mathrm{Ru}_{\mathrm{CUS}}$ sites of (100) and (101) was weakened by 0.04 and $0.18 \mathrm{eV}$, respectively, whereas that of proton-stabilized -OO (6) on the $\mathrm{Ru}_{\mathrm{CUS}}$ sites of (100) and (101) was weakened by 0.15 and $0.34 \mathrm{eV}$, respectively, relative to (110). On the other hand, $-\mathrm{OH}$ had the same binding energy for (100) and (101) and was found to be only $0.04 \mathrm{eV}$ more stable on (110). As proton-stabilized -OO (6) was weakened more greatly than that of $-\mathrm{O}(4)$ on the $\mathrm{Ru}_{\mathrm{CUS}}$ site of (100) relative to (110), the RDS involving the removal of the final proton-stabilizing -OO intermediate for $(110)^{18}$ was found to be isoenergetic with the $-\mathrm{OOH}$ formation step (within the uncertainty of DFT) for the (100) surface (Fig. 2). However, further decreasing the binding energy of the stabilized -OO intermediate and simultaneously weakening -O species on the $\mathrm{Ru}_{\mathrm{CUS}}$ site of (101) changes the OER RDS to the dissociation of the second water molecule on a fully oxidized surface $\left(-\mathrm{O}+\mathrm{H}_{2} \mathrm{O}-\left(\mathrm{H}^{+}+\mathrm{e}^{-}\right) \rightarrow-\mathrm{OO}-\mathrm{H}\right)$. These DFT-calculated energetics suggest that, on the basis of reaction free energies (that is, excluding additional kinetic barriers), different surface adsorbates should be stabilized on the $\mathrm{Ru}_{\mathrm{CUS}}$ site at $1.5 \mathrm{~V}_{\text {DFT-RHE}}$, where the (100) surface could have -O or -OO species and the (101) surfaces should have $-\mathrm{O}$ species. Under oxygen evolution potentials $\left(>1.5 \mathrm{~V}_{\mathrm{RHE}}\right)$, when all steps are thermodynamically downhill, additional kinetic barriers may exist, as calculated in the recent work of Dickens et al. ${ }^{33}$. However, based on the Brønsted-Evans-Polanyi 

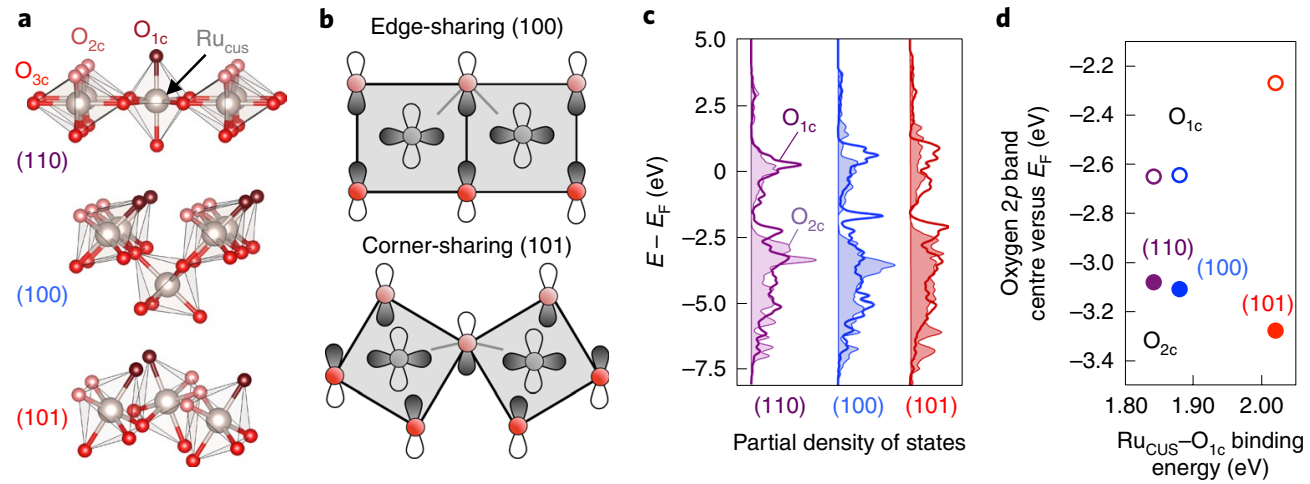

Fig. 1 | The coordination and electronic structure of surface ruthenium and oxygen atoms on different facets of $\mathrm{RuO}_{2}$. $\mathbf{a}$, Schematics depicting the arrangement of undercoordinated ruthenium ( $\mathrm{Ru}_{\mathrm{cus}}$, grey), undercoordinated bridging oxygen $\left(\mathrm{O}_{2 c}\right.$, pink), adsorbed oxygen $\left(\mathrm{O}_{1 c}\right.$, dark red) and fully coordinated bulk oxygen $\left(\mathrm{O}_{3 c}\right.$ red) sites for the different surfaces. The $\mathrm{Ru}_{\mathrm{cus}}$ site on the (110) facet is coordinated to zero $\mathrm{O}_{2 \mathrm{c}}$ atoms, whereas it is coordinated to two $\mathrm{O}_{2 c}$ atoms for the (100) and (101) facets. b. Schematics of the equatorial plane of the (100) and (101) surfaces. The octahedra share an edge for the (100) surface and a corner for the (101) surface, forming a larger $\mathrm{Ru}_{\mathrm{cus}}-\mathrm{O}_{2 \mathrm{c}}-\mathrm{Ru}_{\mathrm{cus}}$ bond angle of $129^{\circ}$ in contrast to $101^{\circ}$. The larger bond angle allows for a higher orbital overlap between $\mathrm{Ru}_{\mathrm{cus}}$ and $\mathrm{O}_{2 c}$. c. The electron density of states for the oxygen $2 p$ orbitals of the $\mathrm{O}_{2 c}$ atoms (shaded) on a stoichiometric surface (no $\mathrm{O}_{1 c}$ atoms) and for the $\mathrm{O}_{1 c}$ atoms on a fully oxidized surface. $\mathbf{d}$, The oxygen $2 p$ band centre for the $\mathrm{O}_{2 c}$ bridging oxygen (closed points) is lowered with an increase in the number of undercoordinated $\mathrm{O}_{2 c}$ oxygen atoms bonded to $\mathrm{Ru}_{\mathrm{cus}}$ and the $\mathrm{Ru}_{\mathrm{cus}}-\mathrm{O}_{2 c}-\mathrm{Ru}_{\mathrm{cus}}$ bond angle. By principle of bond order conservation, the $\mathrm{O}_{1 c}$ oxygen $2 p$ band centre (open points) increases with a decrease in the $\mathrm{O}_{2 c} 2 p$ band centre, which is accompanied by a weaker $\mathrm{Ru}_{\mathrm{Cus}}-\mathrm{O}_{1 \mathrm{c}}$ binding energy. The ruthenium $4 d$ density of states is shown in Supplementary Fig. 1, whereas the Bader charges are shown in Supplementary Fig. 3 and Supplementary Tables 1 and 2.

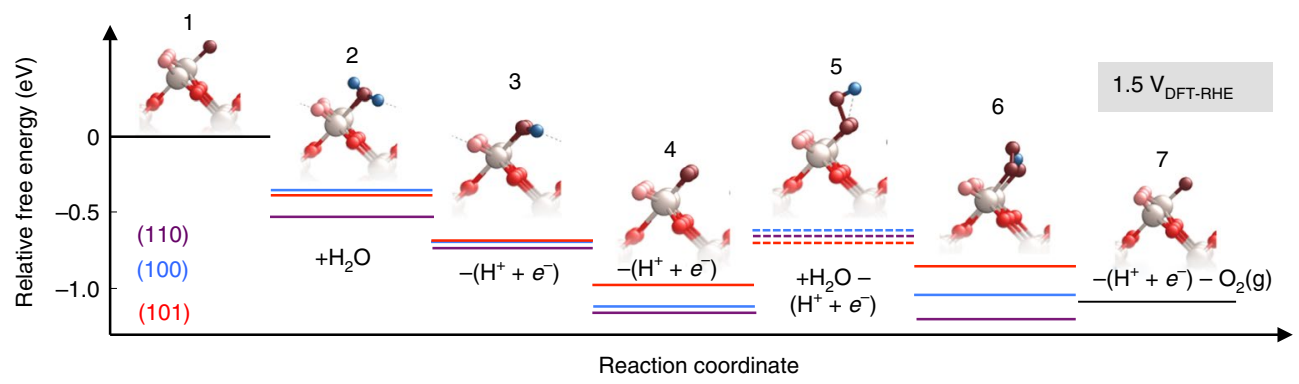

Fig. 2 | A DFT-calculated reaction free energy diagram at $1.5 \mathrm{~V}_{\text {DFT-RHE. }} A$ DFT-calculated free energy diagram for the OER mechanism at $1.5 \mathrm{~V}_{\text {DFT-RHE }}$ (Supplementary Tables 3, 15 and 16), showing the six possible intermediates for the (110) (ref. $\left.{ }^{18}\right),(100)$ and (101) surfaces. The dashed lines indicate unstable- $\mathrm{OOH}$ precursor states, which are needed for $-\mathrm{OO}-\mathrm{H}$ formation. The schematics for the intermediates on the (100) surface are shown. Grey, ruthenium; blue, hydrogen; dark red, $\mathrm{O}_{1 c} ;$ pink, $\mathrm{O}_{2 c}$; red, $\mathrm{O}_{3 c}$.

relationship ${ }^{34}$, we expect that these kinetic barriers will scale with the reaction free energies presented here. This notion is supported by the correlation between the experimental and thermodynamic overpotential plotted in Fig. 2.

Operando X-ray scattering of $\mathrm{RuO}_{2}(100)$ and (101). Operando synchrotron-based surface X-ray scattering crystal truncation rod (CTR) analysis coupled with DFT computation was used to reveal adsorbates on $\mathrm{Ru}_{\mathrm{CuS}}$ for the surface of single crystals with the (100) and (101) termination in $0.1 \mathrm{M} \mathrm{HClO}_{4}$. Here the surface normal is referred to as the (001) direction and the two in-plane directions as (100) and (010) for all of the surface orientations. Surface diffraction data exhibited distinct changes in the anti-Bragg region for the $(10 L)$ rod (at Miller index values of $L=1.5,3.5$ for (100) (Fig. $3 \mathrm{a}-\mathrm{c}$ ), and at $L \approx 1.5$ for (101) (Fig. $4 \mathrm{a}-\mathrm{c}$ )) at $1.0 \mathrm{~V}_{\mathrm{RHE}}, 1.3 \mathrm{~V}_{\mathrm{RHE}}$ and $1.5 \mathrm{~V}_{\mathrm{RHE}}$. The other specular and off-specular rods for the (100) (Supplementary Fig. 5) and (101) (Supplementary Fig. 6) surfaces showed no distinct changes as a function of potential, confirming that the surface does not undergo any reconstruction or roughening during the course of the measurements $(\sim 10 \mathrm{~h})$. This is also consistent with our previous work ${ }^{19}$ showing that terrace sites are not as prone to dissolution as highly undercoordinated defect sites, resulting in a Faradaic efficiency of dissolution of $\sim 0.02 \%$ for single-crystal surfaces (with a corresponding $s$ number, defined as the number of oxygen molecules evolved per dissolved ruthenium $^{35}$, of $\left.\sim 5,000\right)$. Detailed surface models to fit the specular and off-specular data, fitting constraints and results and sensitivity of fit analysis are shown in Supplementary Note 3. Inferences about the nature of the oxygenated species were made based on the fitted bond length between the $\mathrm{Ru}_{\mathrm{CUS}}$ site and adsorbed oxygen atoms. In addition, DFT was used to compute the energetics of different surface structures as a function of potential (Supplementary Tables 15 and 16). By considering the surface structure with the lowest Gibbs free energy in a given potential window from DFT and the $\mathrm{Ru}_{\mathrm{Cus}}-\mathrm{O}$ distance detected for the (100) and (101) surfaces at $1.0 \mathrm{~V}_{\mathrm{RHE}}$, $1.3 \mathrm{~V}_{\mathrm{RHE}}$ and $1.5 \mathrm{~V}_{\mathrm{RHE}}$, molecular descriptions of surface adsorbates on $\mathrm{Ru}_{\mathrm{CUS}}$ - that are compatible with both the DFT and model-based fitting of experimental surface diffraction spectra-were proposed.

The bond length between $\mathrm{Ru}_{\mathrm{CUS}}$ and apically adsorbed oxygenated $\left(\mathrm{Ru}_{\mathrm{Cus}}-\mathrm{O}_{1 \mathrm{c}}\right)$ species for the (100) surface decreased markedly from $2.85 \AA$ at $1.0 \mathrm{~V}_{\mathrm{RHE}}$ to $2.00 \AA$ at $1.3 \mathrm{~V}_{\mathrm{RHE}}$, whereas the bond length between $\mathrm{Ru}_{\mathrm{CUs}}$ and undercoordinated equatorial oxygen 

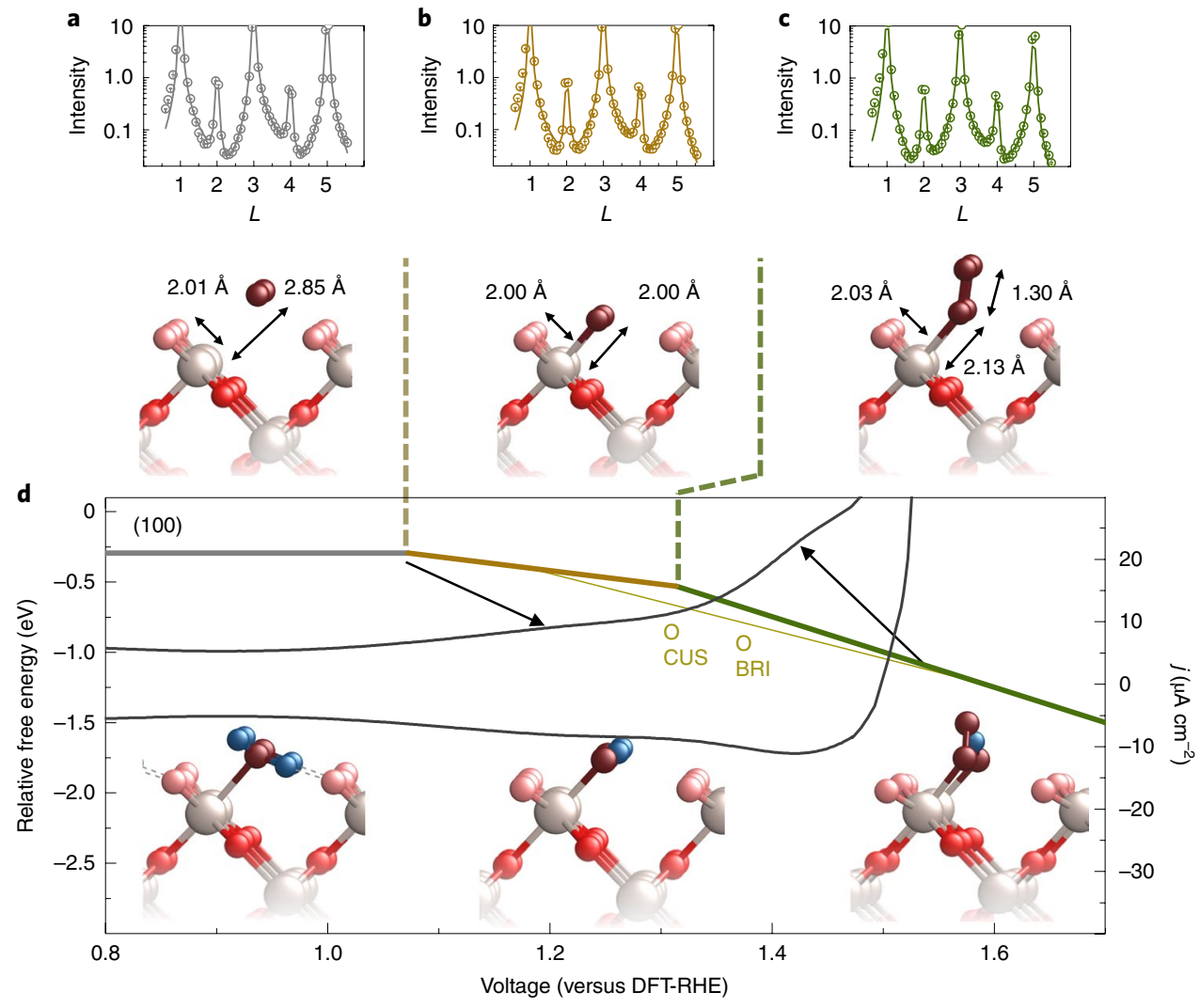

Fig. 3 | Potential-dependent surface structures for $\mathrm{RuO}_{2}$ (100). a-c, The (10L) rod (other rods can be found in Supplementary Fig. 5) measured for the (100) surface at $1.0 \mathrm{~V}_{\mathrm{RHE}}(\mathbf{a}), 1.3 \mathrm{~V}_{\mathrm{RHE}}(\mathbf{b})$ and $1.5 \mathrm{~V}_{\mathrm{RHE}}(\mathbf{c})$ shows changes in the symmetry of the intensities about the Bragg peak $L=2$ as a function of potential. Structures corresponding to the experimentally fitted data show a decrease in the $\mathrm{Ru}_{\mathrm{CUS}}-\mathrm{O}_{1 \mathrm{c}}$ bond length from $1.0 \mathrm{~V}_{\mathrm{RHE}}$ to $1.3 \mathrm{~V}_{\mathrm{RHE}}$, with the formation of an $-\mathrm{OO}$ species at $1.5 \mathrm{~V}_{\mathrm{RHE}}$. Fitted parameters and results are shown in Supplementary Tables 5-8, and bond lengths with error bars are shown in Supplementary Table 9. d, A DFT-generated diagram that shows the relative Gibbs free energies of the most stable adsorbate configurations as a function of electrochemical potential (Supplementary Table 15 shows the computed free energy of all surface structures considered). The transition from one structure to another is representative of an experimentally observed redox transition. At low potentials, water is stabilized on the $\mathrm{Ru}_{\mathrm{cus}}$ site, which is deprotonated to form -OH at $1.05 \mathrm{~V}_{\mathrm{DFT} \text {-RHE }}$ and subsequently deprotonated to form - $\mathrm{O}$. At $1.5 \mathrm{~V}_{\mathrm{DFT}-\mathrm{RHE}}$ an $-\mathrm{OO}$ group is stabilized on the $\mathrm{Ru}_{\mathrm{CUS}}$ site by an $-\mathrm{OH}$ group on a neighbouring $\mathrm{Ru}_{\mathrm{BRI}}$ or $\mathrm{Ru}_{\mathrm{CU}}$ site, with these two configurations being energetically degenerate. An experimental cyclic voltammogram (grey curve) of the (100) facet measured at $50 \mathrm{mV} \mathrm{s}^{-1}$ in argon-saturated $0.1 \mathrm{M} \mathrm{HClO}_{4}$ is shown for reference. Black arrows link the DFT-predicted redox transitions to experimentally observed redox peak positions.

$\left(\mathrm{Ru}_{\mathrm{CuS}}-\mathrm{O}_{2 \mathrm{c}}\right)$ remained unchanged (within the experimental and modeling uncertainty) from $1.0 \mathrm{~V}_{\text {RHE }}$ to $1.3 \mathrm{~V}_{\mathrm{RHE}}$ ( 2.00 ̊; Fig. 3a,b). This change can be attributed to the dissociation of the adsorbed $-\mathrm{H}_{2} \mathrm{O}$ to form $-\mathrm{OH}$ on $\mathrm{Ru}_{\text {Cus }}$, which is in agreement with DFT results that show the deprotonation of adsorbed $-\mathrm{H}_{2} \mathrm{O}$ on $\mathrm{Ru}_{\mathrm{CUS}}$ at potentials greater than $\sim 1.05 \mathrm{~V}_{\text {DFT-RHE }}$ (Fig. $3 \mathrm{~d}$ ). This assignment is further supported by the reasonably good agreement between the experimental redox peak at $\sim 1.2 \mathrm{~V}_{\mathrm{RHE}}$ (grey curve, Fig. $3 \mathrm{~d}$ ) and the corresponding DFT-computed potential at $\sim 1.05 \mathrm{~V}_{\text {DFT-RHE }}$. This difference between experimental and theoretical redox potentials is within the range of values previously reported for rutile $\mathrm{IrO}_{2}$ (ref. ${ }^{25}$ ) and $\mathrm{RuO}_{2}$ (ref. ${ }^{11}$ ), possibly due to uncertainties in the calculations. By contrast, the $\mathrm{Ru}_{\mathrm{CUS}}-\mathrm{O}_{1 \mathrm{c}}$ bond lengths for (101) were comparable at 1.0 and $1.3 \mathrm{~V}_{\mathrm{RHE}}\left(2.04 \AA\right.$ and $1.99 \AA$, respectively). The $\mathrm{Ru}_{\mathrm{CUS}}-\mathrm{O}_{2 \mathrm{c}}$ bond length changed from $2.01 \AA$ at $1.0 \mathrm{~V}_{\mathrm{RHE}}$ to $1.99 \AA$ at $1.3 \mathrm{~V}_{\mathrm{RHE}}$ (Fig. $4 \mathrm{a}, \mathrm{b})$. As the bond length of $\mathrm{O}_{1 \mathrm{c}}$ with $\mathrm{Ru}_{\mathrm{CUS}}$ is larger than bulk apical $\mathrm{Ru}-\mathrm{O}$ bond $(1.905 \AA)$, but shorter than computed $\mathrm{Ru}_{\mathrm{CUS}}-\mathrm{O}$ bond for adsorbed water $(\sim 2.26 \AA)^{22}$, we propose that $\mathrm{Ru}_{\mathrm{CUS}}$ is filled with an $-\mathrm{OH}$ group at $1.0 \mathrm{~V}_{\mathrm{RHE}}$ and $1.3 \mathrm{~V}_{\mathrm{RHE}}$. DFT calculations show the deprotonation of the equatorial bridging oxygen $\mathrm{O}_{2 \mathrm{c}}$ occurs at $\sim 1.0 \mathrm{~V}_{\text {DFT-RHE }}$ while the $\mathrm{Ru}_{\mathrm{CUS}}$ site remained filled with $-\mathrm{OH}$ (Fig. 4d). The experimental redox transition for this facet is not well defined but occurs over a broad range from $\sim 1.05 \mathrm{~V}_{\mathrm{RHE}}$ to $\sim 1.25 \mathrm{~V}_{\mathrm{RHE}}$ (grey curve, Fig. 4d), which is in agreement with the predicted transition potential by DFT. Our results show that, irrespective of the water dissociation tendency on $\mathrm{Ru}_{\mathrm{CUS}}$ at $1.0 \mathrm{~V}_{\mathrm{RHE}}$ (undissociated on (100), partially dissociated on (110) and fully dissociated on (101)), all three facets were found to have $-\mathrm{OH}$ on $\mathrm{Ru}_{\mathrm{CUS}}$ and a fully oxygenated equatorial $\mathrm{O}_{2 \mathrm{c}}$ site at $1.3 \mathrm{~V}_{\mathrm{RHE}}$ (see Supplementary Fig. 19-21 for a comparison of bond lengths and angles).

Further increasing the potential to $1.5 \mathrm{~V}_{\mathrm{RHE}}$ resulted in a surface structure where an -OO was present on the $\mathrm{Ru}_{\mathrm{CuS}}$ site of the (100) surface, as has been reported recently for (110) ${ }^{18}$ (Fig. 3c), and on $\operatorname{IrO}_{2}(110)^{36}$, which is in agreement with DFT results showing proton-stabilized -OO species at $1.5 \mathrm{~V}_{\text {DFT-RHE, }}$ (Figs. 2 and $3 \mathrm{~d}$ ). The assignment is further supported by the experimentally observed redox peak at $\sim 1.45 \mathrm{~V}_{\mathrm{RHE}}$, just before the onset of OER and also in agreement with previous X-ray absorption spectroscopy results on $\mathrm{RuO}_{2}$ particles, where a downshift in the whiteline of the ruthernium $L$-edge was observed before the OER, supporting the formation of an $-\mathrm{OOH}$ like species ${ }^{37}$. We note that without the presence of an -OO group on the $\mathrm{Ru}_{\mathrm{CUS}}$ of the (100) surface, a structure with a short $\mathrm{Ru}_{\mathrm{CUS}}-\mathrm{O}_{1 \mathrm{c}}$ bond length of $1.68 \AA$ and a larger figure of merit is obtained (0.113), compared with the best-fit solution (0.087) with the -OO group (Supplementary Fig. 14). Unlike (110) and (100), a completely oxidized surface was detected on the (101) surface at 

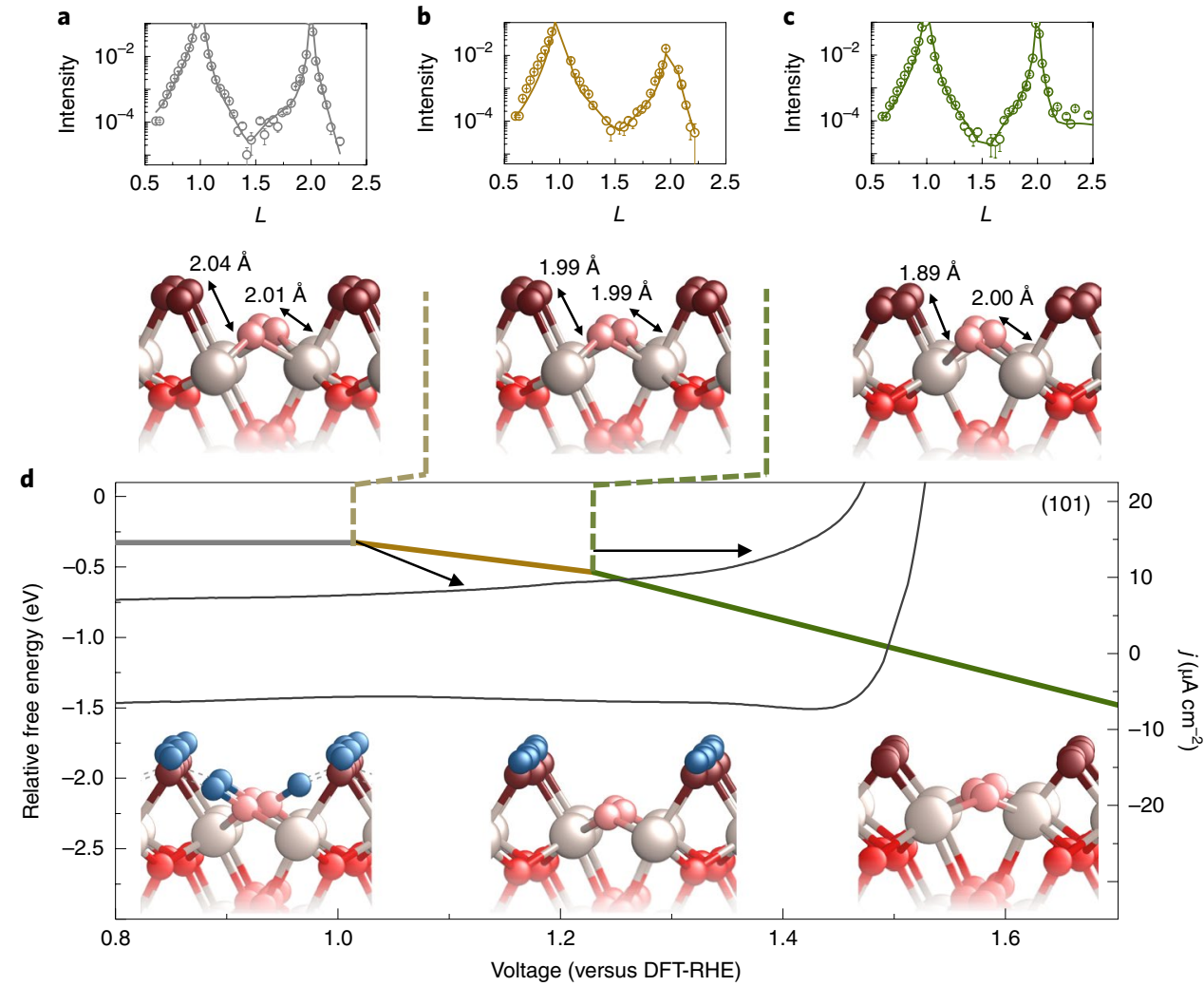

Fig. 4 | Potential-dependent surface structures for $\mathrm{RuO}_{2}(101)$. a-c, The (10L) rod (other rods in Supplementary Fig. 6) measured on the (101) surface at $1.0 \mathrm{~V}_{\mathrm{RHE}}(\mathbf{a}), 1.3 \mathrm{~V}_{\mathrm{RHE}}(\mathbf{b})$ and $1.5 \mathrm{~V}_{\mathrm{RHE}}(\mathbf{c})$ shows changes in the shape of the anti-Bragg position at $L \approx 1.5$. Structures corresponding to the experimentally fitted data show a decrease in the $\mathrm{Ru}_{\mathrm{CUS}}-\mathrm{O}_{1 \mathrm{C}}$ bond length from $1.0 \mathrm{~V}_{\mathrm{RHE}}$ to $1.5 \mathrm{~V}_{\mathrm{RHE}}$. Fitted parameters and results are shown in Supplementary Tables $11-13$ and bond lengths with error bars are shown in Supplementary Table 14. d, A DFT-generated diagram showing the relative Gibbs free energy of the most stable adsorbate configurations as a function of electrochemical potential (Supplementary Table 16 shows the computed free energy of all surface structures considered). The energetics of different adsorbates for the (101) facet suggests the presence of an $-\mathrm{OH}$ group on the $\mathrm{Ru}_{\mathrm{CUS}}$ site with a protonated bridging oxygen at $1.0 \mathrm{~V} \mathrm{VFF}_{\mathrm{RHE}}$. Increasing the potential results in the deprotonation of the bridging oxygen and further increasing the potential to $1.5 \mathrm{~V}_{\mathrm{DFT} \text {-RHE }}$ results in a deprotonation of the $-\mathrm{OH}$ group on the $\mathrm{Ru}_{\mathrm{cus}}$ site to form -O. An experimental cyclic voltammogram (grey curve) of the (101) facet measured at $50 \mathrm{mV} \mathrm{s}^{-1}$ in argon-saturated $0.1 \mathrm{M}$ $\mathrm{HClO}_{4}$ is shown for reference. Black arrows link the DFT-predicted redox transitions to experimentally observed redox peak positions.

$1.5 \mathrm{~V}_{\mathrm{RHE}}$. The $\mathrm{Ru}_{\mathrm{CUS}}-\mathrm{O}_{1 \mathrm{c}}$ bond length was found to be $1.89 \AA$, which is $0.1 \AA$ lower than that found at $1.3 \mathrm{~V}_{\mathrm{RHE}}$, whereas the distance to undercoordinated equatorial oxygen is unchanged from the value at $1.3 \mathrm{~V}_{\mathrm{RHE}}(2.00 \AA)$ (Fig. $4 \mathrm{c}$ ). This experimental finding is in agreement with our DFT results showing a fully oxidized surface structure at $1.5 \mathrm{~V}_{\text {DFT-RHE }}$ (Fig. $4 \mathrm{~d}$ ). The weaker adsorption of $-\mathrm{O}$ and $-\mathrm{OOH}$ on the $\mathrm{Ru}_{\text {CUS }}$ site of (101) compared with (110) and (100) changed the $\mathrm{RDS}$ to $\left(-\mathrm{O}+\mathrm{H}_{2} \mathrm{O}-\left(\mathrm{H}^{+}+\mathrm{e}^{-}\right) \rightarrow-\mathrm{OO}-\mathrm{H}\right)$, which validates the fully oxidized surface measured at $1.5 \mathrm{~V}_{\mathrm{RHE}}$. Although our DFT results predict that the redox transition corresponding to deprotonation of $-\mathrm{OH}$ on $\mathrm{Ru}_{\mathrm{CUS}}$ to form $-\mathrm{O}$ occurs at $\sim 1.22 \mathrm{~V}_{\mathrm{DFT}-\mathrm{RHE}}$, experimentally, a fully hydroxylated $\mathrm{Ru}_{\mathrm{CUS}}$ was detected at $1.3 \mathrm{~V}_{\mathrm{RHE}}$ for the (101) surface. On the basis of our experimental findings from (1) CTR, which suggest a surface structural transition between $1.3 \mathrm{~V}_{\mathrm{RHE}}$ and $1.5 \mathrm{~V}_{\mathrm{RHE}}$ and (2) the experimental cyclic voltammogram, which shows a redox transition at $\sim 1.45 \mathrm{~V}_{\mathrm{RHE}}$, we rationalize that the discrepancy between experimental and DFT redox transition potentials results from a too strong binding of oxygen predicted by DFT on (101). Our results therefore revealed that decreasing the binding energy on $\mathrm{Ru}_{\mathrm{CUS}}$ from (110) and (100) to (101) resulted in a completely oxidized surface as opposed to an -OO-covered surface, which corresponds to a change in the RDS for OER (Fig. 2).

Surface-dependent OER activity of $\mathbf{R} \mathbf{u}_{\text {cus }}$. Experimentally obtained OER currents were found to increase from (110), (101) to (100) (as demonstrated in Fig. $5 \mathrm{a}$ (in $0.1 \mathrm{M} \mathrm{HClO}_{4}$ ) and Supplementary Fig. 22 (in $1 \mathrm{M} \mathrm{HClO}_{4}$ )). We note that no strong $\mathrm{pH}$ dependence was observed and the OER activity trends observed at room temperature and in $0.1 \mathrm{M} \mathrm{HClO}_{4}$ are valid at lower $\mathrm{pH}$ and temperatures of up to $45^{\circ} \mathrm{C}$. The measured OER activity-defined as the current density measured at $1.53 \mathrm{~V}_{\mathrm{RHE}}$ and $1.60 \mathrm{~V}_{\mathrm{RHE}}$-exhibits a volcano trend with decreasing computed binding energy of -O (step 4 in Fig. 2) on $\mathrm{Ru}_{\mathrm{CUS}}$ (Fig. 5b). These results are corroborated with the predicted OER activity, defined by the overpotential, above which all of the steps will be downhill energetically. The free energy change for steps 6 to $7\left(-\mathrm{OO}-\mathrm{H}-\left(\mathrm{H}^{+}+\mathrm{e}^{-}\right) \rightarrow \mathrm{O}_{2}+{ }^{*}\right)$ decreases with weakening of the adsorbed apical binding on $\mathrm{Ru}_{\mathrm{Cus}}$ from the (110) to (100) surface but a further decrease in the binding strength from (100) to (101) makes steps 4 to 6 $\left(-\mathrm{O}+\mathrm{H}_{2} \mathrm{O}-\left(\mathrm{H}^{+}+\mathrm{e}^{-}\right) \rightarrow-\mathrm{OO}-\mathrm{H}\right)$ uphill in free energy (Fig. 2). The computed overpotential was found to decrease from $0.38 \mathrm{~V}$ on $\mathrm{Ru}_{\mathrm{CUS}}$ of (110) to $0.34 \mathrm{~V}$ on (100) and then increase to $0.39 \mathrm{~V}$ on (101) at $1.5 \mathrm{~V}_{\text {DFT-RHE }}$. A decrease in the computed overpotential by $40 \mathrm{mV}$ from (110) to (100) is in qualitative agreement with a one order of magnitude increase in activity at $1.6 \mathrm{~V}_{\mathrm{RHE}}$, considering a measured Tafel slope of $60 \mathrm{mV}$ per decade. On the other hand, although the $\mathrm{Ru}_{\mathrm{CUS}}$ of (101) was found to have the largest overpotential from DFT, experiments showed an intermediate activity between the (110) and (100) surfaces. The higher activity found experimentally for the $\mathrm{Ru}_{\mathrm{CUS}}$ of (101) can be attributed to the greater roughness 

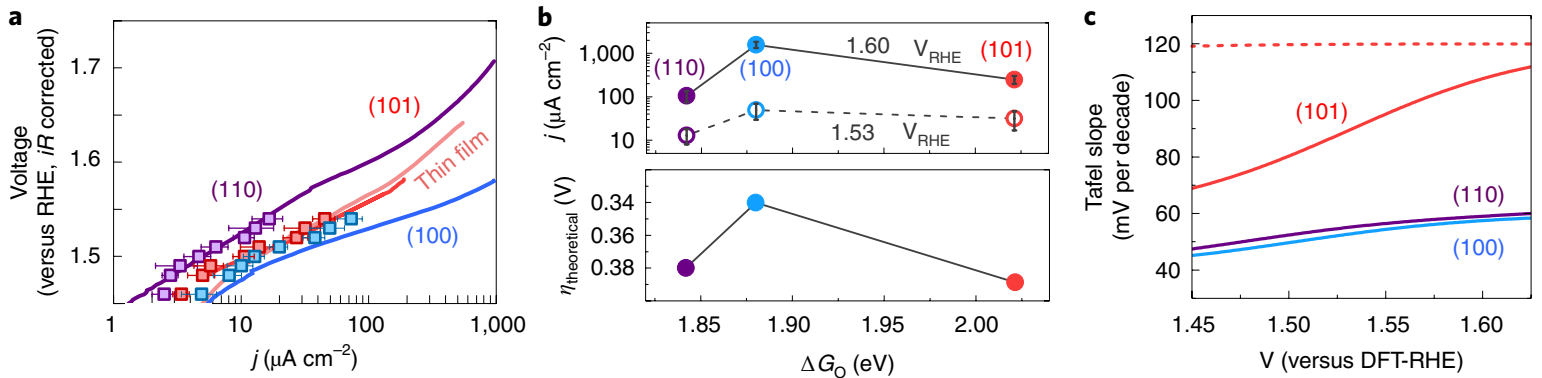

Fig. 5 | Surface-dependent water oxidation kinetics on $\mathbf{R u O}_{2}$. $\mathbf{a}$, Tafel plots of OER activities in $\mathrm{O}_{2}$-saturated $0.1 \mathrm{M} \mathrm{HClO}_{4}$ (data for $1 \mathrm{M} \mathrm{HClO}_{4}$ in Supplementary Fig. 22), measured by cyclic voltammetry at $10 \mathrm{mV} \mathrm{s}^{-1}$ (averaged forwards and backwards, lines) and potentiostatic measurements (constant applied voltage, points). The Tafel slopes for all of the surfaces between $1.5 \mathrm{~V}_{\mathrm{RHE}}$ and $1.6 \mathrm{~V}_{\mathrm{RHE}}$ are $\sim 60 \mathrm{mV}$ per decade $\mathbf{b}$, The current density at $1.53 \mathrm{~V}_{\mathrm{RHE}}$ (potentiostatic measurements) and $1.60 \mathrm{~V}_{\mathrm{RHE}}$ (capacitance corrected cyclic voltammetry) show that the highest OER activity is obtained for the (100) surface. The error bars are obtained from the s.d. of three independent measurements. The theoretical overpotential as a function of the binding energetics of the $-\mathrm{O}$ intermediates. Weakening the $\mathrm{Ru}_{\mathrm{cus}}-\mathrm{O}_{1 \mathrm{c}}$ binding energy reduces the energetic barrier for $-\mathrm{OO}-\mathrm{H}-\left(\mathrm{H}^{+}+\mathrm{e}^{-}\right) \rightarrow \mathrm{O}{ }_{2}+{ }^{\star}(\mathrm{from}(110)$ to

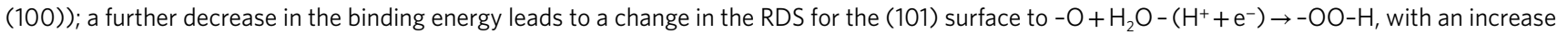
in the theoretical overpotential. c, Predicted Tafel slopes as a function of the potential that results from a difference in coverage of intermediate species before the RDS (Supplementary Table 17 shows the mathematical equations used to obtain the Tafel slopes). The dashed line for the (101) facet represents the values predicted from DFT alone, whereas the solid line for the (101) facet represents the values obtained after accounting for the discrepancy of redox transitions between the theoretically obtained free energy diagrams and experimental cyclic voltammograms.

of this surface $(\sim 2-3 \AA)$, as evidenced by the sharper decay in the CTR signal from the Bragg peak to the anti-Bragg position in the specular rod than the (100) (Supplementary Fig. 5) and (110) ${ }^{18}$ surfaces (Supplementary Fig. 6, Supplementary Tables 11-13), which may expose different sites that have improved binding energetics for the OER intermediates. The volcano trend between thermodynamic binding energetics and the OER activity in this study contrasts with recently reported results on $\mathrm{RuO}_{2}(110)$, where the binding energy of oxygen on the $\mathrm{Ru}_{\mathrm{CUS}}$ site was altered (measured experimentally by changes in the redox peak positions) by changing the solution $\mathrm{pH}^{26}$. These differences could be attributed to the influence of $\mathrm{pH}$ and cations on the reaction mechanism and barriers in addition to differences in binding energy of intermediates ${ }^{38,39}$, which is supported by our previous work on oriented $\mathrm{RuO}_{2}$ surfaces in alkaline solutions which show non-Nernstian $\mathrm{pH}$ dependence of redox peak position and the OER activity ${ }^{27}$.

Experimentally measured Tafel slopes of the OER on (110), (100) and (101) surfaces are in agreement with the energetics of reaction intermediates obtained from DFT. The experimentally measured Tafel slope in the range of $1.5-1.6 \mathrm{~V}_{\mathrm{RHE}}$ was found to be $\sim 60 \mathrm{mV}$ per decade for all of the three surfaces (Fig. 5a), which is consistent with previous experimental work on highly oriented thin films and polycrystalline $\mathrm{RuO}_{2}$ surfaces ${ }^{5,23}$, and estimated Tafel slopes from the reaction mechanism obtained by DFT (Fig. 2) in this study. The Tafel slope was estimated to be ${ }^{40,41} 60 / \alpha \mathrm{mV}$ per decade, where $\alpha$ the transfer coefficient can be given by $\alpha=\frac{n_{f}}{\nu}+n_{r} \beta$, where $n_{\mathrm{f}}$ is the number of electrons transferred per $\mathrm{Ru}_{\mathrm{CUS}}$ site in the step before the RDS in the voltage range of Tafel analysis, $\nu$ is the number of times the RDS occurs for one repetition of the overall cycle (equal to 1 for the OER on all three $\mathrm{RuO}_{2}$ surfaces), $\beta$ is the symmetry factor (assumed to be 0.5 , supported by previous experimentally fitted values for $\mathrm{RuO}_{2}(110)$ single crystals at potentials over $1.52 \mathrm{~V}_{\mathrm{RHE}}$; $\left(\right.$ ref. $\left.{ }^{42}\right)$ ) and $n_{\mathrm{r}}$ is the number of electrons in each occurrence of the $\mathrm{RDS}^{43}$ (equal to 1 for OER on all three $\mathrm{RuO}_{2}$ surfaces; Fig. 2). As DFT predicts that removing the proton stabilizing the -OO on $\mathrm{Ru}_{\mathrm{CUS}}$ was the RDS for the OER on the (110) and (100) surfaces (Fig. 2), the step before RDS, that is the water dissociation on a fully oxidized surface followed by electron-coupled deprotonation, $-\mathrm{O}+\mathrm{H}_{2} \mathrm{O} \rightarrow-\mathrm{OO}-\mathrm{H}+\left(\mathrm{H}^{+}+\mathrm{e}^{-}\right)$was used to determine the coverage of $-\mathrm{O}$ and $-\mathrm{OOH}$ on $\mathrm{Ru}_{\mathrm{CuS}}$ as a function of voltage (more specifically, $\Delta G_{\mathrm{OOH}}$ and $\Delta G_{\mathrm{O}}$, see the Methods section and
Supplementary Note 6 for more details). Having $n_{\mathrm{f}}$ equal to $\theta_{\mathrm{O}}$ on $\mathrm{Ru}_{\text {CUS }}$ results in Tafel slopes varying from $\sim 50$ to $\sim 60 \mathrm{mV}$ per decade for (110) in purple and (100) in blue in the voltage range from 1.45 to $1.60 \mathrm{~V}_{\text {DFT-RHE }}$ (Fig. 5c), in agreement with experimental data (Fig. 5a). Recent work ${ }^{33}$ on the $\mathrm{RuO}_{2}(110)$ surface also related the change in the Tafel slope to the change in the surface coverage; however, their DFT and microkinetic model suggested that the formation of $-\mathrm{OOH}$ was rate-limiting and the surface was covered with $-\mathrm{OH}$ below $\sim 1.5 \mathrm{~V}_{\mathrm{RHE}}$ (corresponding to a Tafel slope of $39 \mathrm{mV}$ per decade) and covered with $-\mathrm{O}$ at higher potentials (corresponding to a Tafel slope of $120 \mathrm{mV}$ per decade). By contrast to the (110) and (100) surfaces, our DFT studies predict a completely oxygenated $\mathrm{Ru}_{\mathrm{CUS}}$ at potentials greater than $1.2 \mathrm{~V}_{\text {DFT-RHE }}$ for (101), where all $\mathrm{Ru}_{\mathrm{CUS}}$ sites are at RDS, resulting in $n_{\mathrm{f}}$ of zero and Tafel slope of $120 \mathrm{mV}$ per decade in the potential range (dashed line in Fig. $5 \mathrm{c}$ ). Considering that CTR for (101) at $1.3 \mathrm{~V}_{\mathrm{RHE}}$ showed $\mathrm{Ru}_{\mathrm{CUS}}$ filled with $-\mathrm{OH}$ (full coverage) and became deprotonated at $1.5 \mathrm{~V}_{\mathrm{RHE}}$, we lowered the computed binding energy of $-\mathrm{O}$ by $0.15 \mathrm{eV}$ to match the experimental redox transition (Fig. 4), which resulted in Tafel slopes increasing from $\sim 70$ to $\sim 110 \mathrm{mV}$ per decade from 1.45 to $1.625 \mathrm{~V}_{\text {DFT-RHE }}$, in an increased agreement with the experimentally observed Tafel slope $(\sim 60 \mathrm{mV}$ per decade), shown as red solid line in Fig. 5c.

Further evidence for the involvement of -OO species in the RDS of the OER came from surface-enhanced infrared absorption (SEIRA) spectroscopy measurements on a polycrystalline $\mathrm{RuO}_{2}$ thin film, as shown in Fig. 6a and Supplementary Figs. 23-26. Below $800 \mathrm{~cm}^{-1}$, the signal was dominated by strong absorption from the silicon prism. On increasing the voltage from $0.5 \mathrm{~V}_{\mathrm{RHE}}$, two peaks at $\sim 1,100 \mathrm{~cm}^{-1}$ and $\sim 1,000 \mathrm{~cm}^{-1}$ were observed, which could be attributed to the $\mathrm{Si}-\mathrm{O}-\mathrm{Si}$ prism $^{44}$ and perchlorate ions at the interface ${ }^{45}$, respectively. At $1.5 \mathrm{~V}_{\mathrm{RHE}}$ and higher, a third peak at $\sim 899 \mathrm{~cm}^{-1}$ appeared. The -OO group on the $\mathrm{Ru}_{\text {CUS }}$ site that is stabilized by an $-\mathrm{OH}$ group on the neighbouring bridge site for $(110)^{18}$ and (100), revealed by CTR and DFT (Fig. 3), is predicted to have an infrared active vibration mode at $910 \mathrm{~cm}^{-1}$ for an $-\mathrm{OO}$ coverage of 0.5 , or at $889 \mathrm{~cm}^{-1}$ if every $\mathrm{Ru}_{\mathrm{CuS}}$ is considered to have an -OO group from DFT (Supplementary Table 18). The peak detected at $\sim 899 \mathrm{~cm}^{-1}$ at OER-relevant potentials can therefore be attributed to proton-stabilized -OO species on a polycrystalline $\mathrm{RuO}_{2}$ surface. This assignment is further supported by measurements in deuterated solutions that reveal a shift in the frequency to 


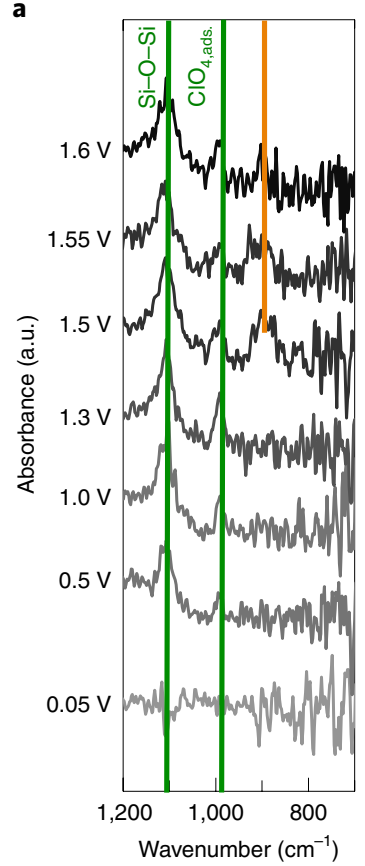

b

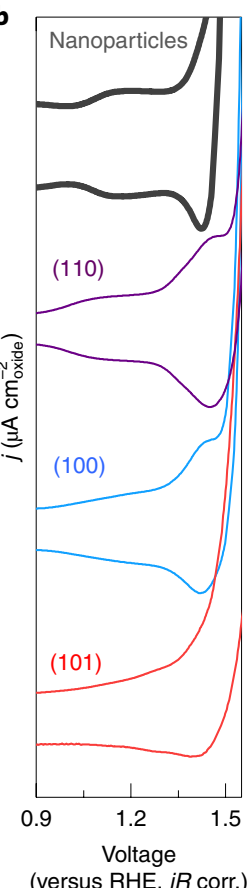

(versus RHE, iR corr.)

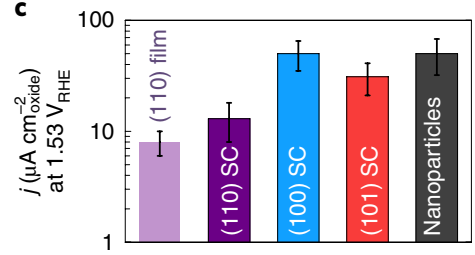

Fig. 6 | The reaction mechanism and water oxidation activity on polycrystalline $\mathrm{RuO}_{2}$ surfaces. a, A SEIRA spectra for a polycrystalline $\mathrm{RuO}_{2}$ surface (Supplementary Fig. 26 shows results in deuterated solutions). Si-O-Si (ref. ${ }^{44}$ ) and adsorbed perchlorate ion ${ }^{45}$ peaks are present irrespective of potential. At potentials higher than $1.50 \mathrm{~V}_{\mathrm{RHE}}$ an additional peak appears at $899 \mathrm{~cm}^{-1}$ that corresponds to the formation of an $-\mathrm{OO}$ group on the $\mathrm{Ru}_{\text {cus }}$ site, interacting with a neighbouring protonated bridging oxygen (Supplementary Table 18 lists the theoretical frequency for all structures considered). b, A comparison of the cyclic voltammograms of $\mathrm{RuO}_{2}$ nanoparticles to oriented single-crystal surfaces. Measurements were made in argon-saturated $0.1 \mathrm{M} \mathrm{HClO}_{4}$ at $50 \mathrm{mV} \mathrm{s}^{-1}$. c, A comparison of the OER activity at $1.53 \mathrm{~V}_{\text {RHE }}$ between (110) thin films ${ }^{26}$ (extrapolated on the basis of data from 1.55-1.65 $\mathrm{V}_{\mathrm{RHE}}$ assuming a constant Tafel slope), (110), (100) and (101) single crystals (SCs), and the nanoparticles reported here (Supplementary Fig. 28 shows a Tafel plot of the activity between $1.45 \mathrm{~V}_{\text {RHE }}$ and $1.65 \mathrm{~V}_{\mathrm{RHE}}$ (all measured in $0.1 \mathrm{M} \mathrm{HClO}_{4}$ )). The error bars are obtained from the s.d. of three independent measurements.

$815 \mathrm{~cm}^{-1}$, confirming the strong interaction of the -OO group with a neighbouring hydrogen/deuterium atom (Supplementary Fig. 26, Supplementary Table 18).

Implications for $\mathrm{RuO}_{2}$ nanoparticles. Single-crystal $\mathrm{RuO}_{2}(110)$ (ref. ${ }^{18}$ ), thin films of $\mathrm{RuO}_{2}(110)$ grown using molecular beam epitaxy ${ }^{26}$ and single-crystal $\mathrm{RuO}_{2}(100)$ exhibit a redox peak at $\sim 1.2 \mathrm{~V}_{\mathrm{RHE}}$ in $0.1 \mathrm{M} \mathrm{HClO}_{4}$ (Fig. 6b), which can be attributed to deprotonation of adsorbed water to form $-\mathrm{OH}$ (Fig. 3), whereas the redox peak at $\sim 1.45 \mathrm{~V}_{\mathrm{RHE}}$ can be attributed to the adsorption and dissociation of water onto a fully oxidized surface followed by electroncoupled deprotonation to form proton-stabilized -OO (Fig. 3). These two redox transitions were also observed on $\mathrm{RuO}_{2}$ nanoparticles (Sigma-Aldrich, $\sim 25 \mathrm{~nm}$; X-ray diffraction and transmission electron microscopy characterization in Supplementary Fig. 27) in Fig. 6b, which indicates that $\mathrm{Ru}_{\mathrm{CUS}}$ sites from (110) and (100) govern the redox transitions or pseudo-capacitance of $\mathrm{RuO}_{2}$ nanoparticles. Furthermore, the OER activities of $\mathrm{RuO}_{2}$ nanoparticles measured in this study (Supplementary Fig. 28) and in previous work ${ }^{5,19}$ are comparable to $\mathrm{RuO}_{2}(100)$ and (101) but are around five times higher than that of single-crystal ${ }^{18}$ and thin-film ${ }^{26} \mathrm{RuO}_{2}(110)$, as shown in Fig. 6c. Although some $\mathrm{RuO}_{2}$ polycrystalline thin films ${ }^{46}$ and nanoparticles ${ }^{47}$ thermally annealed at temperatures lower than $600^{\circ} \mathrm{C}$ have considerably higher OER activity than these $\mathrm{RuO}_{2}$ single-crystal surfaces, they are not included in the discussion and comparison here as they have more structural defects that are evidenced by broad X-ray diffraction ${ }^{46,47}$. Their stability during the OER over time is also not known, considering that the contribution from the dissolution of ruthenium to the measured OER current increases with lowering the annealing temperature of $\mathrm{RuO}_{2}$ (ref. ${ }^{19}$ ). Our results therefore suggest that the OER activity of highly crystalline $\mathrm{RuO}_{2}$ nanoparticles might be governed by $\mathrm{RuO}_{2}(100)$ and (101) surfaces at OER-relevant potentials. This is also in agreement with previous theoretical work that shows that facets other than the (110) surface govern the activity of the OER at high potentials ${ }^{48,49}$.

\section{Conclusions}

In this study, by combining CTR and DFT, we discuss the role of surface-dependent $\mathrm{Ru}_{\mathrm{CUS}}$ (that is, the active site) in governing the OER reaction mechanism and consequently the overall OER activity. Although (110), (100) and (101) all have $\mathrm{Ru}_{\mathrm{CUS}}$ sites in the same $\mathrm{RuO}_{5}$ coordination, with four neighbouring equatorial oxygen atoms and one apical binding site, the coordination of the equatorial oxygen atoms and the bond angle between $\mathrm{Ru}_{\mathrm{CuS}}$ sites and undercoordinated equatorial oxygen is different, resulting in different energetics of $-\mathrm{O}$ and proton-stabilized -OO for apical binding with a decreasing order from (110), (100) to (101). DFT results show that reducing the binding of the proton-stabilized -OO group on the $\mathrm{Ru}_{\mathrm{Cus}}$ site of (100) relative to (110) lowers the energetic barrier of electron-coupled deprotonation from the $-\mathrm{OO}-\mathrm{H}$ group (the RDS), leading to a greater predicted OER activity for the $\mathrm{Ru}_{\mathrm{CUS}}$ site of (100). On the other hand, further weakening of the binding energy on the $\mathrm{Ru}_{\mathrm{Cus}}$ site of (101) results in the RDS changing to the second water dissociation step on a fully oxidized surface to form a proton-stabilized -OO species, leading to a lower predicted OER activity for the $\mathrm{Ru}_{\mathrm{CUS}}$ site of (101) relative to (100) and (110). The surface-dependent adsorbates on $\mathrm{Ru}_{\text {CUS }}$ at the OER-relevant potentials (as predicted by DFT) were consistent with best-fit surface models obtained from operando surface diffraction measurements. The $\mathrm{Ru}_{\mathrm{CUS}}$ site of (100) has $-\mathrm{H}_{2} \mathrm{O}$ and $-\mathrm{OH}$ adsorbed at 1.1 and $1.3 \mathrm{~V}_{\mathrm{RHE}}$, respectively, whereas the $\mathrm{Ru}_{\mathrm{CuS}}$ site of (101) has $-\mathrm{OH}$ at both voltages. At an OER-relevant potential of $1.5 \mathrm{~V}_{\mathrm{RHE}}$, a combination of DFT and surface diffraction measurements points to an -OO group on the $\mathrm{Ru}_{\mathrm{CUS}}$ site of (100) (similar to the $\mathrm{Ru}_{\mathrm{CUS}}$ site of (110)), but an oxygen-terminated surface for the $\mathrm{Ru}_{\mathrm{CUS}}$ site of (101), and this difference is in agreement with the predicted change in the RDS for different $\mathrm{Ru}_{\mathrm{CUS}}$ sites from DFT. Further evidence of -OO species that are involved in the RDS for the OER comes from SEIRA spectroscopy measurements on polycrystalline $\mathrm{RuO}_{2}$, where we note a vibration mode that corresponds to an -OO intermediate on $\mathrm{Ru}_{\mathrm{CUS}}$. Such mechanistic insights, as well as computed and experimental OER activities of the $\mathrm{Ru}_{\mathrm{CuS}}$ sites from different single-crystal facets, explain the redox properties and OER activities of highly crystalline $\mathrm{RuO}_{2}$ nanoparticles. Directly tuning the electronic structure of surface active sites while maintaining the bulk chemistry opens up new directions in OER catalyst design; for example, understanding the effect of surface crystallographic orientation on the OER activity enables rational design of nanoparticle shapes, where the work of Wang et al. ${ }^{48}$ demonstrates the tunability of Wulff particle shapes for $\mathrm{RuO}_{2}$ surfaces. Further studies are needed to understand how the active site can be further altered by 
systematic control of different defects, which can create $\mathrm{Ru}-\mathrm{O}$ surface coordination environments that are considerably different from the $\mathrm{Ru}_{\mathrm{CUS}}$ sites of (110), (100) and (101), leading to much greater OER activity $^{32,50}$. Moreover, the coordination environment of the active site can also be altered to tune the binding energetics on the active site by cation ${ }^{51-53}$ and/or anion ${ }^{54}$ doping of atoms in the first or second coordination shell of active ruthenium sites, and also by creating different defect sites with unique $\mathrm{Ru}-\mathrm{O}$ surface coordination environment ${ }^{32,50}$ by (electro)chemical treatments. Even more tunability in the coordination environment of surface ruthenium sites can be achieved by designing molecular ruthenium-based chemistries. Here the ligand environment can not only alter the binding energetics of the OER intermediates, but the degree of interaction of these ligands can also modify the $\mathrm{Ru}-\mathrm{Ru}$ distance to allow for an oxygen coupling mechanism between adsorbed oxygens on two adjacent sites ${ }^{55}$, which doesn't require the formation of an $-\mathrm{OOH}$ species that results in an energetic penalty for the overall reaction. A molecular understanding of the influence of the local environment of an active site on the OER reaction mechanism and activity can enable the design of catalysts that surpass the highest activity predicted by traditional bulk electronic structure descriptors.

\section{Methods}

Electrochemistry. Single-crystal $\mathrm{RuO}_{2}$ surfaces were synthesized by oxidative evaporation/redeposition of $\mathrm{RuO}_{2}$ powders as described in refs. ${ }^{56,57}$. The as-grown crystals exhibited few defects, such as twinning or faults, and had a bulk mosaic within $\sim 0.01^{\circ}$ of the perfect crystal and exposed surfaces of (110), (100) and (101) that ranged from $\sim 2 \mathrm{~mm}$ to $5 \mathrm{~mm}$ in size. Furthermore, a bulk crystal was cut by the Princeton Scientific Corporation to expose a (001) facet to an orientation accuracy $<0.1^{\circ}$ and polished to a roughness $<10 \mathrm{~nm}$. Electrical contacts were applied to the back of the crystal, which was mounted in a Teflon mold (FEP 100, DuPont) with the facet under consideration exposed to the electrolyte. For the (101) surface, an epitaxial thin film prepared using pulsed laser deposition (as described in ref. ${ }^{28}$ ) was also used. Nanoparticles were purchased commercially (Sigma-Aldrich, 99.9\% trace metal base). The particle-based film electrodes were prepared by slowly drying catalyst ink prepared using $4 \mathrm{mg}$ acetylene black carbon, $20 \mathrm{mg} \mathrm{RuO}$, $0.12 \mathrm{ml} \mathrm{3.33wt \%} \mathrm{Nafion} \mathrm{solution} \mathrm{and} 3.88 \mathrm{ml}$ tetrahydrofuran; $10 \mu \mathrm{l}$ ink (equivalent to $0.050 \mathrm{mg}_{\text {oxide }}$ ) was dropcast onto a glassy carbon rotating disk electrode (Pine Instrument). A Biologic SP-300 potentiostat and standard three-electrode set-up was used. For each measurement, $\sim 120 \mathrm{ml}$ of $0.1 \mathrm{M} \mathrm{HClO}_{4}$ (70\% Veritas double distilled) was prepared using deionized water (Millipore, $>18.2 \mathrm{M} \Omega \mathrm{cm}$ ) and presaturated with argon for $60 \mathrm{~min}$ to prevent reduction of oxygen at low potentials; argon gas was also left bubbling throughout the measurement. Activity measurements were made in $\mathrm{O}_{2}$-saturated solutions. A $4 \mathrm{M}$ saturated $\mathrm{Ag} / \mathrm{AgCl}$ electrode (Pine) was used (calibrated to the RHE scale) and a large platinum wire was used as the counter electrode. Cyclic voltammetry measurements were performed at $50 \mathrm{mV} \mathrm{s}^{-1}$ and $10 \mathrm{mV} \mathrm{s}^{-1}$, whereas electrical impedance spectroscopy measurements were conducted at open circuit potential with an amplitude of $10 \mathrm{mV}$. The potentials reported versus the RHE are corrected for the electrolyte/cell resistance $(\sim 50 \Omega)$ measured using the high-frequency intercept of the real resistance obtained from the Nyquist plot as well as the $\mathrm{pH}$ of the electrolyte measured using a $\mathrm{pH}$ metre. The electronic resistance between the single-crystal surface and the wire was $<5 \Omega$.

CTR analysis. Surface diffraction measurements were carried out at Beamline 12 ID-D of the Advanced Photon Source, using a similar method described in refs. ${ }^{18,22}$. The single-crystal surfaces were cleaned by electrochemical cycling between $0.2 \mathrm{~V}_{\mathrm{RHE}}$ and $1.55 \mathrm{~V}_{\mathrm{RHE}}$ in $0.1 \mathrm{M} \mathrm{HClO}_{4}$ solution. Specular and off-specular rods were collected using the reflection geometry for each surface at $1.0 \mathrm{~V}_{\mathrm{RHE}}$, $1.3 \mathrm{~V}_{\mathrm{RHE}}$ and $1.5 \mathrm{~V}_{\mathrm{RHE}}$. For a given time, additional rods do not add more information, but increase the signal-to-noise ratio $^{58}$, which can also be obtained by using a longer counting time for the measured rods, as is the case for these measurements. Measurements at high potential were obstructed by evolution of oxygen gas bubbles at the electrode surface. The cell was sealed at the top with an X-ray transparent Kapton foil. To minimize the electrolyte thickness above the sample, air from the cell was sucked out to create a vacuum, using a syringe. Following this, electrolyte was injected through a syringe to form a thin layer above the crystal surface due to capillary forces. The electrolyte used was $0.1 \mathrm{M}$ $\mathrm{HClO}_{4}$ (70\% Veritas double distilled) solution in deionized water (Millipore, $>18.2 \mathrm{M} \Omega \mathrm{cm}$ ). The reference electrode used was a saturated $\mathrm{Ag} / \mathrm{AgCl}$ electrode (Bioanalytical Systems, Inc.) and a platinum counter electrode was used.

The assembled cell was mounted on a Huber five-circle $(3 S+2 \mathrm{D})$ diffractometer. The initial sample alignment was performed using a laser beam to ensure that the sample surface was at a right angle to the main axis of the diffractometer. Specular rods were recorded using a configuration with the incidence angle equal to the exit angle. For the off-specular rods, the incidence angle was fixed at either $2^{\circ}$ or $4^{\circ}$. An orientation matrix was calculated to relate the motor angles to the Miller indices $(h k l)$. The intensities were measured using a pixel area detector (PILATUS $100 \mathrm{~K}$ model). The measured intensities were extracted by integrating the photon counts of the pixels in the region of interest on the detector and were corrected for background noise, illuminated sample surface area, electrolyte thickness and a Lorentz factor that takes into consideration the experimental geometry.

For each surface, a model was created in GenX version 2.4.7 $7^{59}$, as discussed in Supplementary Note 3 . At each potential, $\sim 200-300$ symmetrically independent data points were used for the fitting (Figs. 3 and 4, Supplementary Figs. 5 and 6). The surface model used for the fitting of the (100) data is provided in Supplementary Figs. 7 and 8, and Supplementary Table 5 lists the fitting parameters. Similarly, Supplementary Figs. 9 and 10 show the fitting model used for the (101) surface, and Supplementary Table 10 lists the fitting parameters. For the (100) and (101) surfaces, the adsorbed oxygen atoms were constrained to maintain the bulk bond angle and the validity of this assumption is supported by a good agreement between the CTR bond angle between $\mathrm{Ru}_{\mathrm{CUs}}$ and $\mathrm{O}_{1 \mathrm{c}}$, and the corresponding DFT and bulk bond angles shown in Supplementary Fig. 21. Apart from this constraint, all of the other parameters chosen for the CTR analysis are not cross-correlated (that is, allowed to relax independently) to create the simplest model without any a priori assumptions. The figure of merit (FOM) to be minimized is shown in equation (1):

$$
\mathrm{FOM}_{\operatorname{logR1}}=\frac{\sum_{i}\left|\log \left(\sqrt{Y_{i}}\right)-\log \left(\sqrt{S_{i}}\right)\right|}{\sum_{i}\left|\log \left(\sqrt{Y_{i}}\right)\right|}
$$

where $Y_{i}$ is the experimentally measured intensity for point $i$ and $S_{i}$ is the simulated intensity. All rods were fitted simultaneously and a value $<0.10$ was obtained for al conditions, signifying a reliable fit (Supplementary Tables 6-8 for the (100) surface and Supplementary Tables 11-13 for the (101) surface). Uncertainties in the bond lengths were obtained by running the simulation ten different times with different initial conditions. The four best simulation results were used to compute the average atomic positions and their s.d, following the method described in ref. ${ }^{60}$. Simulated spectra for various $\mathrm{Ru}-\mathrm{O}_{2 \mathrm{c}}$ and $\mathrm{Ru}-\mathrm{O}_{1 \mathrm{c}}$ bond lengths are shown in Supplementary Figs. 11-15 for the (100) surface and in Supplementary Figs. 16-18 for the (101) surface. CTR fitting was also carried out on data for the (001) facet (Supplementary Figs. 29-35, Supplementary Tables 19-23, Supplementary Note 9); however, the significant loss of intensity at the anti-Bragg regions suggests a larger surface roughness compared with the (110) and (100) facets, and thus this surface is not included in our analysis.

Surface-enhanced IR spectroscopy. Platinum was first deposited on a silicon plate via an electroless deposition method ${ }^{61}$. $\mathrm{RuO}_{2}$ was sputtered on this film using a ruthenium target at a deposition rate of $\sim 0.7 \mathrm{~A} \mathrm{~s}^{-1}$ under $\mathrm{Ar}: \mathrm{O}_{2}=7: 5$ s.c.c.m., total pressure $3 \mathrm{mTorr}$, at $450^{\circ} \mathrm{C}$, resulting in a thickness of $\sim 30 \mathrm{~nm}$. X-ray diffraction (Supplementary Fig. 23) and X-ray photoelectron spectroscopy (Supplementary Fig. 24) confirm the presence of rutile $\mathrm{RuO}_{2}$, which was then pressed against the flat plane of a hemispherical ZnSe prism (radius $22 \mathrm{~mm}$, Pier optics) to increase the signal-to-noise ratio in the lower wavenumber region (that is, lower than $1,400 \mathrm{~cm}^{-1}$ ). This prism was then mounted in a spectroelectrochemical three-electrode cell. An $\mathrm{Ag} / \mathrm{AgCl}$ reference electrode and a large surface area platinum wire counter electrode was used. The SEIRA spectra were obtained on a FT-IR Vertex 70 (Bruker) equipped with a mercury cadmium telluride detector (Supplementary Figs. 25 and 26); $\mathrm{N}_{2}$ was used to fully replace the optical path. The resolution for the measurements was $4 \mathrm{~cm}^{-1}$ and 1,024 scans were averaged for each condition. The SEIRA spectra were recorded using a single-reflection attenuated total reflection accessory (Pike Vee-Max II, Pike Technologies) with a silicon plate/ZnSe prism at an incident angle of $65^{\circ}$. Further experimental details are described elsewhere ${ }^{62,63}$.

Computational methods. The Vienna ab initio simulation package ${ }^{64,65}$, using the Perdew-Burke-Ernzerhof functional ${ }^{66}$ and projector augmented-wave projectors ${ }^{67,68}$, was used for the DFT calculations. A cut-off energy of $500 \mathrm{eV}$ was chosen and a $6 \times 6 \times 1$ Monkhorst-Pack $k$-point sampling ${ }^{69}$ was used for the super cell. The super cell used for each orientation was a $1 \times 2$ replication performed along the short axis of the cell. This allowed for symmetry breaking and adsorbateadsorbate interactions. The Gibbs free energies were calculated by correcting the DFT obtained energies for the zero-point energy and vibrational entropy. The contributions of all atoms beyond the fully reduced surface were considered for the zero-point energy and vibrational entropy contributions. The adsorbed species were referenced to tabulated values of gas-phase hydrogen and water at the gasliquid interface at $0.035 \mathrm{bar}$ and $300 \mathrm{~K}$ respectively $\mathrm{y}^{70}$. The computational hydrogen electrode described by Nørskov has been used to represent the data on the RHE scale. The gas-phase $\mathrm{O}_{2}$ reference is calculated using ${ }^{71}$ equation (2):

$$
0.5 \times G_{\mathrm{O}_{2}(\mathrm{~g})}=G_{\mathrm{H}_{2} \mathrm{O}(\mathrm{g})}-G_{\mathrm{H}_{2}(\mathrm{~g})}-\Delta G_{\exp }
$$

Supplementary Tables 15, 16 and 24 contain the DFT results for the (100), (101) and (001) surfaces, respectively. The atomic coordinates of the optimized models are provided in Supplementary Data 1. 
Theoretical Tafel slope analysis. The only potential-dependent term, $n_{\mathrm{f}}$, used in the estimation of Tafel slope came from potential-dependent coverage of reaction intermediates from DFT (Supplementary Table 17, Supplementary Note 6). At any given potential, the surface coverage of these intermediates must also sum to unity; for example, for the (110) and (100) facets, $\theta_{\mathrm{OOH}}+\theta_{\mathrm{O}}=1$. The surface coverage of $-\mathrm{O}$ and $-\mathrm{OOH}$ as a function of potential is given by $\theta_{\mathrm{OOH}}=\theta_{\mathrm{O}} e^{\frac{-\left(\Delta G_{\mathrm{OOH}}-\Delta G_{\mathrm{O}}\right)}{R T}}$, where $\Delta G_{\mathrm{OOH}}-\Delta G_{\mathrm{O}}$ is a function of potential, as can be seen in Fig. 3 for the (100) surface and ref. ${ }^{18}$ for the (110) surface. The value of $n_{\mathrm{f}}$ is given by the number of electrons that must be transferred for each active site to be filled with $-\mathrm{OOH}$; thus, for these two surfaces, $n_{\mathrm{f}}=\theta_{\mathrm{O}}$, as each site that is filled with $-\mathrm{O}$ will have to lose one electron to be converted to -OOH. Every site filled with -OOH can participate in the RDS without further transfer of electrons. For the (101) surface, the RDS is $-\mathrm{O}+\mathrm{H}_{2} \mathrm{O}-\left(\mathrm{H}^{+}+\mathrm{e}^{-}\right) \rightarrow-\mathrm{OO}-\mathrm{H}$. Considering that CTR measurements of $(101)$ at $1.3 \mathrm{~V}_{\mathrm{RHE}}$ showed that the $\mathrm{Ru}_{\mathrm{CUS}}$ site is filled with $-\mathrm{OH}$ (full coverage) that became deprotonated at $1.5 \mathrm{~V}_{\mathrm{RHE}}$, we lowered the computed binding energy of -O by $0.15 \mathrm{eV}$ to match the experimental redox transition (Fig. 4). In this case, the $-\mathrm{O}$ species is formed by deprotonation of $-\mathrm{OH},-\mathrm{OH}-\left(\mathrm{H}^{+}+\mathrm{e}^{-}\right) \rightarrow-\mathrm{O}$. The surface coverage of $-\mathrm{O}$ and $-\mathrm{OH}$ are related by $\theta_{\mathrm{O}}=\theta_{\mathrm{OH}} \mathrm{e}^{\frac{-\left(\Delta G_{\mathrm{O}}-\Delta G_{\mathrm{OH}}\right)}{R T}}$, where $\Delta G_{\mathrm{O}}-\Delta G_{\mathrm{OH}}$ is potential dependent as seen in Fig. 4. At any given potential, the surface coverage of $-\mathrm{OH}$ and $-\mathrm{O}$ must also follow the relation, $\theta_{\mathrm{OH}}+\theta_{\mathrm{O}}=1$. In this case, the value of $n_{\mathrm{f}}$ is equal to the surface coverage of $-\mathrm{OH}$ species, as each $-\mathrm{OH}$ species would have to lose one electron to reach the RDS $n_{\mathrm{f}}=\theta_{\mathrm{OH}}$. We note that the surface would become saturated with the intermediates before the RDS at larger overpotentials than the range considered here, resulting in a value of $n_{\mathrm{f}}=0$ and a Tafel slope of $120 \mathrm{mV}$ per decade.

\section{Data availability}

The data supporting the findings of this study are available in the paper and its Supplementary Information. Extra data are available from the corresponding authors on reasonable request.

Received: 22 September 2019; Accepted: 27 March 2020; Published online: 11 May 2020

\section{References}

1. Gray, H. B. Powering the planet with solar fuel. Nat. Chem. 1, 7 (2009).

2. Andersen, S. Z. et al. A rigorous electrochemical ammonia synthesis protocol with quantitative isotope measurements. Nature 570, 504-508 (2019).

3. Liu, C., Colón, B. C., Ziesack, M., Silver, P. A. \& Nocera, D. G. Water splitting-biosynthetic system with $\mathrm{CO}_{2}$ reduction efficiencies exceeding photosynthesis. Science 352, 1210-1213 (2016).

4. Zhang, J., Zhao, Z., Xia, Z. \& Dai, L. A metal-free bifunctional electrocatalyst for oxygen reduction and oxygen evolution reactions. Nat. Nanotechnol. 10, 444-452 (2015).

5. Lee, Y., Suntivich, J., May, K. J., Perry, E. E. \& Shao-Horn, Y. Synthesis and activities of rutile $\mathrm{IrO}_{2}$ and $\mathrm{RuO}_{2}$ nanoparticles for oxygen evolution in acid and alkaline solutions. J. Phys. Chem. Lett. 3, 399-404 (2012).

6. Over, H. Surface chemistry of ruthenium dioxide in heterogeneous catalysis and electrocatalysis: from fundamental to applied research. Chem. Rev. 112, 3356-3426 (2012).

7. Chu, Y. S., Lister, T. E., Cullen, W. G., You, H. \& Nagy, Z. Commensurate water monolayer at the $\mathrm{RuO}_{2}(110) /$ water interface. Phys. Rev. Lett. 86, 3364-3367 (2001).

8. Calle-Vallejo, F. et al. Finding optimal surface sites on heterogeneous catalysts by counting nearest neighbors. Science 350, 185-189 (2015).

9. Nørskov, K. J. et al. The nature of the active site in heterogeneous metal catalysis. Chem. Soc. Rev. 37, 2163-2171 (2008).

10. Sun, Q., Reuter, K. \& Scheffler, M. Effect of a humid environment on the surface structure of $\mathrm{RuO}_{2}(110)$. Phys. Rev. B 67, 205424 (2003).

11. Abbott, D. F. et al. Oxygen reduction on nanocrystalline ruthenia-local structure effects. RSC Adv. 5, 1235-1243 (2014).

12. Over, H. et al. Atomic-scale structure and catalytic reactivity of the $\mathrm{RuO}_{2}(110)$. Surf. Sci. 287, 1474-1476 (2000).

13. Over, H. et al. Visualization of atomic processes on ruthenium dioxide using scanning tunneling microscopy. ChemPhysChem 5, 167-174 (2004).

14. Madhavaram, $\mathrm{H}$. et al. Oxidation reactions over $\mathrm{RuO}_{2}$ : a comparative study of the reactivity of the (110) single crystal and polycrystalline surfaces. J. Catal. 202, 296-307 (2001)

15. Exner, K. S., Anton, J., Jacob, T. \& Over, H. Full kinetics from first principles of the chlorine evolution reaction over $\mathrm{a} \mathrm{RuO}_{2}(110)$ model electrode. Angew. Chem. Int. Ed. 55, 7501-7504 (2016).

16. Wang, Y., Jacobi, K., Schöne, W.-D. \& Ertl, G. Catalytic oxidation of ammonia on $\mathrm{RuO}_{2}(110)$ surfaces: mechanism and selectivity. J. Phys. Chem. B 109, 7883-7893 (2005)

17. Wang, Y., Jacobi, K. \& Ertl, G. Interaction of NO with the stoichiometric $\mathrm{RuO}_{2}(110)$ surface. J. Phys. Chem. B 107, 13918-13924 (2003).

18. Rao, R. R. et al. Towards identifying the active sites on $\mathrm{RuO}_{2}(110)$ in catalyzing oxygen evolution. Energy Environ. Sci. 10, 2626-2637 (2017).
19. Roy, C. et al. Trends in activity and dissolution on $\mathrm{RuO}_{2}$ under oxygen evolution conditions: particles versus well-defined extended surfaces. ACS Energy Lett. 3, 2045-2051 (2018).

20. $\mathrm{Mu}, \mathrm{R}$. et al. Deprotonated water dimers: the building blocks of segmented water chains on rutile $\mathrm{RuO}_{2}(110)$. J. Phys. Chem. C 119, 23552-23558 (2015).

21. $\mathrm{Mu}, \mathrm{R}$. et al. Dimerization induced deprotonation of water on $\mathrm{RuO}_{2}(110)$. J. Phys. Chem. Lett. 5, 3445-3450 (2014).

22. Rao, R. R. et al. Surface orientation dependent water dissociation on rutile ruthenium dioxide. J. Phys. Chem. C 122, 17802-17811 (2018).

23. Stoerzinger, K. A., Qiao, L., Biegalski, M. D. \& Shao-Horn, Y. Orientation-dependent oxygen evolution activities of rutile $\mathrm{IrO}_{2}$ and $\mathrm{RuO}_{2}$. J. Phys. Chem. Lett. 5, 1636-1641 (2014).

24. Hepel, T., Pollak, F. H. \& O'Grady, W. E. Effect of crystallographic orientation of single-crystal $\mathrm{RuO}_{2}$ electrodes on the hydrogen adsorption reactions. J. Electrochem. Soc. 131, 2094-2100 (1984).

25. Kuo, D.-Y. et al. Influence of surface adsorption on the oxygen evolution reaction on $\mathrm{IrO}_{2}(110)$. J. Am. Chem. Soc. 139, 3473-3479 (2017).

26. Kuo, D.-Y. et al. Measurements of oxygen electroadsorption energies and oxygen evolution reaction on $\mathrm{RuO}_{2}(110)$ : a discussion of the sabatier principle and its role in electrocatalysis. J. Am. Chem. Soc. 140, 17597-17605 (2018)

27. Stoerzinger, K. A. et al. The role of $\mathrm{Ru}$ redox in $\mathrm{pH}$-dependent oxygen evolution on rutile ruthenium dioxide. Surf. Chem. 2, 668-675 (2017).

28. Stoerzinger, K. A. et al. Orientation-dependent oxygen evolution on $\mathrm{RuO}_{2}$ without lattice exchange. ACS Energy Lett. 2, 876-881 (2017).

29. Lee, Y.-L., Kleis, J., Rossmeisl, J., Shao-Horn, Y. \& Morgan, D. Prediction of solid oxide fuel cell cathode activity with first-principles descriptors. Energy Environ. Sci. 4, 3966-3970 (2011)

30. Grimaud, A. et al. Activating lattice oxygen redox reactions in metal oxides to catalyse oxygen evolution. Nat. Chem. 9, 457-465 (2017).

31. Kim, Y. D., Schwegmann, S., Seitsonen, A. P. \& Over, H. Epitaxial growth of $\mathrm{RuO}_{2}(100)$ on $\mathrm{Ru}(10 \mathrm{I0})$ : surface structure and other properties. J. Phys. Chem. B 105, 2205-2211 (2001).

32. Dickens, C. F., Montoya, J. H., Kulkarni, A. R., Bajdich, M. \& Nørskov, J. K. An electronic structure descriptor for oxygen reactivity at metal and metal-oxide surfaces. Surf. Sci. 681, 122-129 (2019).

33. Dickens, C. F., Kirk, C. \& Nørskov, J. K. Insights into the electrochemical oxygen evolution reaction with ab initio calculations and microkinetic modeling: beyond the limiting potential volcano. J. Phys. Chem. C 123, 18960-18977 (2019).

34. Vojvodic, A. et al. On the behavior of Brønsted-Evans-Polanyi relations for transition metal oxides. J. Chem. Phys. 134, 244509 (2011).

35 . Geiger, S. et al. The stability number as a metric for electrocatalyst stability benchmarking. Nat. Catal. 1, 508-515 (2018).

36. Ping, Y., Nielsen, R. J. \& Goddard, W. A. The reaction mechanism with free energy barriers at constant potentials for the oxygen evolution reaction at the $\mathrm{IrO}_{2}$ (110) surface. J. Am. Chem. Soc. 139, 149-155 (2017).

37. Pedersen, A. F. et al. Operando XAS study of the surface oxidation state on a monolayer $\mathrm{IrO}_{x}$ on $\mathrm{RuO}_{x}$ and Ru oxide based nanoparticles for oxygen evolution in acidic media. J. Phys. Chem. B 122, 878-887 (2018).

38. Jensen, K. D. et al. Elucidation of the oxygen reduction volcano in alkaline media using a copper-platinum(111) alloy. Angew. Chem. Int. Ed. 57, 2800-2805 (2018).

39. Rizo, R., Herrero, E. \& Feliu, M. J. Oxygen reduction reaction on stepped platinum surfaces in alkaline media. Phys. Chem. Chem. Phys. 15, 15416-15425 (2013)

40. Böckris, J., Reddy, A. \& Gamboa-Aldeco, M. Modern Electrochemistry, 2A: Fundamentals of Electrodics (Springer, 2000).

41. Bockris, J. O. Kinetics of activation controlled consecutive electrochemical reactions: anodic evolution of oxygen. J. Chem. Phys. 24, 817-827 (1956).

42. Castelli, P., Trasatti, S., Pollak, F. H. \& O'Grady, W. E. Single crystals as model electrocatalysts: oxygen evolution on $\mathrm{RuO}_{2}$ (110). J. Electroanal. Chem. Interfacial Electrochem. 210, 189-194 (1986).

43. Bard, A. J., Faulkner, L. R., Leddy, J. \& Zoski, C. G. Electrochemical Methods: Fundamentals and Applications Vol. 2 (Wiley, 1980).

44. Guiton, T. A. \& Pantano, C. G. Infrared reflectance spectroscopy of porous silicas. Colloids Surf. Physicochem. Eng. Asp. 74, 33-46 (1993).

45. Huang, Y.-F., Kooyman, P. J. \& Koper, M. T. M. Intermediate stages of electrochemical oxidation of single-crystalline platinum revealed by in situ Raman spectroscopy. Nat. Commun. 7, 12440 (2016).

46. Frydendal, R. et al. Benchmarking the stability of oxygen evolution reaction catalysts: the importance of monitoring mass losses. ChemElectroChem 1, 2075-2081 (2014).

47. Paoli, E. A. et al. Oxygen evolution on well-characterized mass-selected Ru and $\mathrm{RuO}_{2}$ nanoparticles. Chem. Sci. 6, 190-196 (2014).

48. Wang, T., Jelic, J., Rosenthal, D. \& Reuter, K. Exploring pretreatmentmorphology relationships: ab initio Wulff construction for $\mathrm{RuO}_{2}$ nanoparticles under oxidising conditions. ChemCatChem 5, 3398-3403 (2013). 
49. Wang, T. \& Reuter, K. Structure sensitivity in oxide catalysis: first-principles kinetic Monte Carlo simulations for CO oxidation at $\mathrm{RuO}_{2}(111)$. J. Chem. Phys. 143, 204702 (2015).

50. Dickens, C. F. \& Nørskov, J. K. A theoretical investigation into the role of surface defects for oxygen evolution on $\mathrm{RuO}_{2}$. J. Phys. Chem. C 121, 18516-18524 (2017).

51. Halck, N. B., Petrykin, V., Krtil, P. \& Rossmeisl, J. Beyond the volcano limitations in electrocatalysis-oxygen evolution reaction. Phys. Chem. Chem. Phys. 16, 13682-13688 (2014).

52. Chen, D., Fang, Y.-H. \& Liu, Z.-P. Searching for active binary rutile oxide catalyst for water splitting from first principles. Phys. Chem. Chem. Phys. 14, 16612-16617 (2012)

53. Lin, Y. et al. Chromium-ruthenium oxide solid solution electrocatalyst for highly efficient oxygen evolution reaction in acidic media. Nat. Commun. 10, 162 (2019).

54. Kadakia, K., Datta, M. K., Jampani, P. H., Park, S. K. \& Kumta, P. N. Novel F-doped $\mathrm{IrO}_{2}$ oxygen evolution electrocatalyst for PEM based water electrolysis. J. Power Sources 222, 313-317 (2013).

55. Duan, L. et al. A molecular ruthenium catalyst with water-oxidation activity comparable to that of photosystem II. Nat. Chem. 4, 418-423 (2012).

56. Lister, T. E. et al. Cathodic activation of $\mathrm{RuO}_{2}$ single crystal surfaces for hydrogen-evolution reaction. J. Electroanal. Chem. 554-555, 71-76 (2003).

57. Lister, T. E. et al. Electrochemical and X-ray scattering study of well defined $\mathrm{RuO}_{2}$ single crystal surfaces. J. Electroanal. Chem. 524-525 201-218 (2002).

58. Gründer, Y. \& Lucas, C. A. Surface X-ray diffraction studies of single crystal electrocatalysts. Nano Energy 29, 378-393 (2016).

59. Björck, M. \& Andersson, G. GenX: an extensible X-ray reflectivity refinement program utilizing differential evolution. J. Appl. Crystallogr. 40 1174-1178 (2007).

60. Petach, T. A. et al. Voltage-controlled interfacial layering in an ionic liquid on $\mathrm{SrTiO}_{3}$. ACS Nano 10, 4565-4569 (2016).

61. Miki, A., Ye, S. \& Osawa, M. Surface-enhanced IR absorption on platinum nanoparticles: an application to real-time monitoring of electrocatalytic reactions. Chem. Commun. 1500-1501 (2002)..

62. Osawa, M., Yoshii, K., Ataka, K. \& Yotsuyanagi, T. Real-time monitoring of electrochemical dynamics by submillisecond time-resolved surface-enhanced infrared attenuated-total-reflection spectroscopy. Langmuir 10, 640-642 (1994).

63. Chen, Y. X., Miki, A., Ye, S., Sakai, H. \& Osawa, M. Formate, an active intermediate for direct oxidation of methanol on Pt electrode. J. Am. Chem. Soc. 125, 3680-3681 (2003).

64. Kresse, G. \& Hafner, J. Ab initio molecular dynamics for liquid metals. Phys. Rev. B 47, 558-561 (1993).

65. Kresse, G. \& Furthmüller, J. Efficiency of ab-initio total energy calculations for metals and semiconductors using a plane-wave basis set. Comput. Mater Sci. 6, 15-50 (1996).

66. Perdew, J. P., Burke, K. \& Ernzerhof, M. Generalized gradient approximation made simple. Phys. Rev. Lett. 77, 3865-3868 (1996).

67. Blöchl, P. E. Projector augmented-wave method. Phys. Rev. B 50, 17953-17979 (1994)

68. Kresse, G. \& Joubert, D. From ultrasoft pseudopotentials to the projector augmented-wave method. Phys. Rev. B 59, 1758-1775 (1999).

69. Monkhorst, H. J. \& Pack, J. D. Special points for Brillouin-zone integrations. Phys. Rev. B 13, 5188-5192 (1976).
70. M. W. Chase et al. NIST-JANAF Thermochemical Tables v.1.0 (National Institute of Standards and Technology, 1985); https://janaf.nist.gov/janbanr.html

71. Nørskov, J. K. et al. Origin of the overpotential for oxygen reduction at a fuel-cell cathode. J. Phys. Chem. B 108, 17886-17892 (2004).

\section{Acknowledgements}

This work was supported in part by the Toyota Research Institute through the Accelerated Materials Design and Discovery programme. We thank B. Han for transmission electron microscopy characterization of $\mathrm{RuO}_{2}$ nanoparticles and J. Corchado-Garcia for help during the CTR data collection. This work was supported in part by the Skoltech-MIT Center for Electrochemical Energy and the Cooperative Agreement between the Masdar Institute, UAE and the Massachusetts Institute of Technology, USA (grant no. 02/MI/MIT/CP/11/07633/GEN/G/00). The work by H.Y. was supported by US Department of Energy (DOE), Basic Energy Sciences (BES), Materials Sciences and Engineering Division, and the work by H.Z. and the use of the Advanced Photon Source were supported by DOE, BES, Scientific User Facility Division (SUFD) under contract no. DE-AC02-06CH11357. The work by A.M. was supported by DOE, BES, SUFD under contract no. DE-AC02-76SF00515. A.F.P. acknowledges the Danish Ministry for Higher Education and Science for an EliteForsk travel grant and the Strategic Research's project NACORR (grant no. 12-133817). This work used the Extreme Science and Engineering Discovery Environment (XSEDE), which is supported by National Science Foundation grant no. ACI-154856283. This research also used resources of the National Energy Research Scientific Computing Center, a DOE Office of Science User Facility supported by the Office of Science of the US DOE under contract no. DE-AC02-05CH11231. T.V. and N.B.H acknowledge support through V-Sustain: the VILLUM Centre for the Science of Sustainable Fuels and Chemicals (grant no. 9455) from VILLUM FONDEN. I.E.L.S acknowledges the Peabody Visiting Associate Professorship, awarded by the Department of Mechanical Engineering at Massachusetts Institute of Technology.

\section{Author contributions}

Y.S.H. and R.R.R. conceived and designed the experiments. R.R.R. performed the electrochemical measurements. R.R.R., A.F.P., J.H., A.M., H.Y. and H.Z. participated in the surface diffraction measurements. M.J.K., L.G., J.R.L., N.B.H. and T.V. performed the DFT calculations and analysis. Y.K., J.H. and R.R.R. performed the in situ surface-enhanced FT-IR spectroscopy measurements. I.E.L.S. and I.C. participated in the discussion and interpretation of experimental and theoretical data. Y.S.H. and R.R.R. wrote the manuscript. All of the authors discussed the results and commented on the manuscript.

\section{Competing interests}

The authors declare no competing interests.

\section{Additional information}

Supplementary information is available for this paper at https://doi.org/10.1038/ s41929-020-0457-6.

Correspondence and requests for materials should be addressed to R.R.R. or Y.S.-H. Reprints and permissions information is available at www.nature.com/reprints. Publisher's note Springer Nature remains neutral with regard to jurisdictional claims in published maps and institutional affiliations.

(c) The Author(s), under exclusive licence to Springer Nature Limited 2020 